University of Michigan Law School

University of Michigan Law School Scholarship Repository

Law \& Economics Working Papers

$1-1-2013$

\title{
Explaining Variation in Insurance Anti-Discrimination Laws
}

\author{
Ronen Avraham \\ University of Texas at Austin, ravraham@law.utexas.edu \\ Kyle D. Logue \\ University of Michigan Law School, klogue@umich.edu \\ Daniel Benjamin Schwarcz \\ University of Minnesota Law School, schwarcz@umn.edu
}

Follow this and additional works at: https://repository.law.umich.edu/law_econ_current

Part of the Insurance Law Commons

\section{Working Paper Citation}

Avraham, Ronen; Logue, Kyle D.; and Schwarcz, Daniel Benjamin, "Explaining Variation in Insurance AntiDiscrimination Laws" (2013). Law \& Economics Working Papers. 82.

https://repository.law.umich.edu/law_econ_current/82

This Article is brought to you for free and open access by University of Michigan Law School Scholarship Repository. It has been accepted for inclusion in Law \& Economics Working Papers by an authorized administrator of University of Michigan Law School Scholarship Repository. For more information, please contact mlaw.repository@umich.edu. 


\title{
Explaining Variation in Insurance Anti-Discrimination Laws
}

\author{
Ronen Avraham (University of Texas at Austin) \\ Kyle D. Logue (University of Michigan) \\ Daniel Schwarcz (University of Minnesota)
}

* This paper has benefited from comments received at workshops at Emory Law School, Northwestern University School of Law, UCLA School of Law, Virginia School of Law, The University of Texas School of Law, and ITAM (Mexico). We are especially grateful for comments from Kenneth Abraham, Tom Baker, Albert Choi, Joey Fishkin, Cary Franklin, Martin Grace, David Hyman, Stefanie Lindquist, Larry Sager and Charlie Silver. Nathaniel Lipanovich and Rachel Ezzell provided excellent research assistance. We are also thankful to Faculty Services Reference Librarian Seth Quidachay-Swan and his team of law students at the University of Michigan Law School. 


\section{Introduction}

During the last fifty years state and federal laws have prohibited numerous types of discrimination. In the case of insurance, however, discrimination on the basis of traits such as race, national origin, gender, and sexual orientation is not always prohibited. ${ }^{1}$ Sometimes such discrimination is even expressly permitted by state law, which, at least outside of the health insurance domain, is the predominant source of law on insurance discrimination. With fifty states (plus the District of Columbia) all regulating insurance companies, insurance antidiscrimination law varies widely. In a previous article, we empirically demonstrated the specific contours of this variation, which exists not simply across states, but also across lines of insurance and policyholder characteristics. In this paper, we attempt to explain why this cross-line and cross-characteristic variation occurs.

This inquiry is motivated by the seemingly puzzling contours of state insurance anti-discrimination laws. For instance, why is state regulation of discrimination in the automobile and property lines of insurance more robust than in the cases of health, life, or disability insurance? Why are insurance companies allowed to use gender in health insurance underwriting decisions, but not in automobile insurance? Why do states (and the federal government) prohibit insurers' use of genetic information in health insurance, but hardly regulate the use of such information for other lines of insurance?

At a high level of abstraction, the answer to these and other puzzles is simply that laws regulating insurance discrimination represent different tradeoffs between the "efficiency" costs of regulation and the "fairness" benefits. ${ }^{2}$ We have little quarrel with this framing of the issue. But it is too generic to helpfully explain or predict state law, as numerous types of efficiency and fairness arguments can be offered in any particular case. As we showed in our earlier paper, these factors pull in different directions and make it hard to predict when and how a state will regulate particular forms of discrimination in a given line of insurance.

\footnotetext{
${ }^{1}$ See Avraham, Logue \& Schwarcz, Understanding Insurance Anti-Discrimination Laws, Southern California Law Review (forthcoming, 2014).

${ }^{2}$ See, e.g., Kenneth S. Abraham, Efficiency and Fairness in Insurance Risk Classification, 71 VA. L. REV. 403 (1985); Michael Hoy \& Michael Ruse, Regulating Genetic Information in Insurance Markets, 8 RISK MGMT. \& INS. REV. 211 (2005) ("Economists can contribute to the debate [about regulating genetic information in insurance markets] by casting the problem as a classic efficiency-equity trade-off.").
} 
In this paper we narrow our discussion and focus on two types of efficiency considerations and one fairness consideration to understand state insurance antidiscrimination laws. The first efficiency consideration involves the capacity of a potential trait to predict policyholder losses. Irrespective of applicable law, insurers are not likely to discriminate among policyholders unless doing so helps them to better predict potentially insured losses. The second efficiency consideration is adverse selection: prohibiting risk classification forces insurers to charge the same premiums to individuals who pose different predicted risks. ${ }^{3}$ This can produce adverse selection, as policyholders who know they cannot be charged more for insurance even if they possess a risky trait may be more likely to buy coverage because they will not pay its full price. ${ }^{4}$ Finally, the fairness benefit on which we focus is that insurance anti-discrimination laws can prohibit carriers from relying on characteristics that are socially suspect, thus preventing insurers from exacerbating or trading on inequalities that exist outside of the insurance system (loosely characterized here as preventing insurers from illicitly discriminating).

We argue that these three factors, standing alone, can predict much of the cross-line and cross-characteristic variation in state insurance anti-discrimination law. This is very surprising. One would expect that lots of the variation depends on state specific circumstances like the preferences of the constituents regarding questions of discrimination, the ideology of the legislature, the strength of the insurance lobby, and a host of other socio-economic factors that are unique to each state. As we show below, one can abstract from all these factors and still have a pretty good understanding on what explains insurance anti-discrimination laws in the U.S. In particular, we advance the following simple three-prong model to understand how state legislatures strike a balance between the efficiency and fairness considerations involved in insurance discrimination:

a) The predictive property - State legislatures will be more likely to consider regulating (either by prohibiting or permitting) risk

\footnotetext{
${ }^{3}$ For an overview of insurance law, including a detailed discussion of moral hazard and adverse selection, see Ronen Avraham, The Economics of Insurance Law-A Primer, 19 ConN. INS. L.J. 29 (2012).

${ }^{4}$ To be sure, insurers will classify risks even without the threat of adverse selection, because competition from other carriers will otherwise skim away the good risks. This does not represent a social cost, however, unless it causes at least some policyholders to purchase less insurance than they would like to purchase at actuarially fair rates.
} 
classification based on a characteristic (like age) if that characteristic has predictive value for policyholder risk. ${ }^{5}$

b) The adverse selection property - State legislatures will tend to allow risk classification to the extent that limiting such discrimination would be likely to trigger adverse selection.

c) The illicit discrimination property - State legislatures will be more inclined to prohibit risk classification based on a characteristic (like age) to the extent that doing so would help combat (or appear to combat) illicit discrimination.

These properties must be balanced against each other to determine the outcome of state laws.

Part I provides an overview of the adverse selection, illicit discrimination, and predictive property arguments regarding risk classification. Part II describes briefly the empirical approach that provides the backbone and evidence for this paper. Part III then reviews various cross-line and cross-characteristic variations in state insurance laws that are difficult to explain. It then applies the model detailed above and in Part I to explain much of this variation.

\section{Part I: Overview}

\section{A. Insurers' Usage of Policyholders' Characteristics}

Laws forbidding the use of a characteristic in underwriting may be hard to justify if insurers are not actually discriminating among policyholders on the basis of that characteristic. ${ }^{6}$ To some extent, though, this depends on why insurers are not using the relevant characteristic.

First, if insurers do not use a rating characteristic because it has no apparent predictive value, then the case for legally restricting the use of this characteristic is

\footnotetext{
${ }^{5}$ State legislatures therefore tend to not regulate risk classifications when insurers have anyway no economic incentives to do it because the characteristics convey no relevant information for that line of insurance. An example for that is sexual orientation in automobile insurance.

${ }^{6}$ Evidence suggests that states often do pass coverage mandates that have no practical effect because all known insurance plans are consistent with those mandates. See Amy Monahan, Fairness Versus Welfare in Health Insurance Content Regulation, 2012 U. ILL. L. REV. 139 (2012).
} 
extremely weak. Insurers are unlikely to ever use a characteristic with no predictive power in underwriting, meaning that the only social benefit such a law might provide is to articulate a moral commitment to a principle. But such a law could produce potentially meaningful social costs in the form of the public cost of legislating and the private cost of policing compliance. ${ }^{7}$

Second, the case for regulation may be slightly stronger when the reason that carriers do not use a policyholder characteristic is because the cost of determining and verifying the characteristic outweighs the benefits of a more refined classification scheme. ${ }^{8}$ Here, a plausible case can be made for laws restricting insurers' usage of characteristics that are predictive of risk, but nonetheless not used because of the cost to insurers of evaluating that characteristic: even though insurers are not currently employing the troubling characteristic in their underwriting, this may change as the composition of the population or cost of collecting accurate policyholder information changes. Legal prohibitions on risk classification can therefore be justified as a mechanism for preventing potentially problematic insurer behavior in the future.

Finally, the case for regulation is relatively strong if insurers are refraining from using problematic policyholder characteristics because they fear the potential reputational or regulatory consequences of doing so. ${ }^{9}$ There is good evidence that this occurs. For instance, both auto and life insurers often do not take into account policyholder occupation, even though this characteristic has been shown to predict claims and is relatively easy for insurers to determine. ${ }^{10}$ Similarly, long term care insurers do not generally take into account gender, even though this has a

\footnotetext{
${ }^{7}$ It is a common critique of expressivist theories generally that they provide a compelling argument for action only when they happen to coincide with some other type of argument, such as an efficiency or distributive fairnesstype argument. Mathew D. Adler, Expressive Theories of Law: A Skeptical Overview, 148 PENN. L. REV. 3163 (2000). Compliance costs may exist even if insurers are not using the underlying risk characteristic, because the carrier must expend funds confirming that this is not the case.

${ }^{8}$ See generally Amy Finkelstein \& James Porterba, Testing for Adverse Selection with "Unused Observables" (Nat'l Bureau of Econ. Research, Working Paper No. 12112, 2006) (noting that insurers often do not use policyholder characteristics in underwriting even though these characteristics have predictive value, and offering various potential explanations for this phenomenon).

${ }^{9}$ See Finkelstein \& Porterba, supra note 8. Finkelstein and Porterba note a fourth potential explanation: that the predictive content of characteristics such as place of residence may be limited by the extent to which such characteristics are subject to change in response to characteristic-based pricing differentials. As they note, however, this is unlikely to be a substantial factor in most cases because the difficulty of changing the underlying characteristic will generally be larger than the potential insurance benefits of doing so.

${ }^{10}$ See Finkelstein \& Porterba, supra note 8, at 21.
} 
substantial impact on claims experiences. ${ }^{11}$ Evidence that smaller and newer firms have been more willing than established firms to introduce rating innovations suggests that this behavior is partially explained by the fear of public or regulatory backlash; newer and smaller firms are likely to be less deterred by the prospect of reputational or market backlash as a result of risk classification innovation. ${ }^{12}$ In these cases, laws explicitly limiting insurers' ability to employ the suspect characteristics have the benefit of reducing regulatory uncertainty. Of course, a coherent argument can be made that regulation in these settings in neither necessary nor wise: when norms and reputation are sufficient to constrain private behavior, it may be best for law to avoid intervention because of the risk that it may "crowd out" those norms.

\section{B. Adverse Selection}

Adverse selection is a familiar potential efficiency cost of legal restrictions on insurers' risk-classification practices. Indeed, some commentators label adverse selection resulting from legal restrictions on insurers' risk classification practices as "regulatory adverse selection." 14 Such regulatory adverse selection stems from the fact that legal restrictions on insurers' risk classification practices force them to charge the same premiums to high-risk policyholders who possess the illicit trait and low-risk policyholders who do not. This, in turn, can cause high-risk policyholders who cannot be charged more for insurance even though they possess a risky trait to be more likely to buy coverage because they will not pay its full price. ${ }^{15}$ If this occurs, then insurers may respond by charging low-risk individuals premiums that are too high for their risk. Anticipating this sort of inaccuracy in pricing, low-risk individuals may exit the risk pool and opt not to purchase insurance coverage at all, leaving only higher risk (and more expensive) insureds.

\footnotetext{
${ }^{11}$ See Jeffrey Browne \& Amy Finkelstein, The Private Market for Long-Term Care Insurance In The United States: A Review of the Evidence, 76 J. RISK \& Ins. 5 (2009).

${ }^{12}$ See Finkelstein \& Porterba, supra note 8.

${ }^{13}$ See, e.g., Uri Gneezy \& Aldo Rustichini, A Fine Is a Price, 29 J. LEGAL STUD. 1, 3 (2000); Larry E. Ribstein, Law v. Trust, 81 B.U. L. REV. 553, 568-71 (2001).

${ }^{14}$ See Hoy \& Ruse, supra note2, at 245.

${ }^{15}$ To be sure, insurers will classify risks even without the threat of adverse selection, because competition from other carriers will otherwise skim away the good risks. This does not represent a social cost, however, unless it causes at least some policyholders to purchase less insurance than they would like to purchase at actuarially fair rates.
} 
Increasingly substantial empirical research demonstrates that this threat is more contingent on the characteristics of particular insurance markets than has traditionally been assumed. ${ }^{16}$ Some insurance markets are quite susceptible to adverse selection, while others are resistant to adverse selection even if regulations substantially limit the capacity of insurers to classify risks. ${ }^{17}$ For these reasons, a central consideration in determining the desirability of risk-classification restrictions is the extent to which such rules are likely to generate adverse selection "on the ground." At least eight factors are relevant to determining if riskclassification regulation creates a real danger of adverse selection.

First, rules limiting insurers' ability to classify risks are less likely to generate adverse selection when the percentage of high-risk individuals is small relative to the population of potential insureds. ${ }^{18}$ In such cases, compelling insurers not to discriminate against high-risk individuals will result in only a small increase in actuarially-fair pooled premiums, as the characteristics of all policyholders will, on the aggregate, be quite similar to the characteristics of the low-risk policyholders. As such, low-risk individuals will be unlikely to opt out of the insurance pool because the value they derive from complete coverage is larger than this minimally increased cost. Nor will rival firms attempt to appeal to lowrisk individuals by offering incomplete insurance coverage because they can anticipate that such efforts will ultimately prove unprofitable. ${ }^{19}$ Notably, the effect of regulation may be small in these cases, if even in the absence of regulation

\footnotetext{
${ }^{16}$ Peter Siegelman, Adverse Selection in Insurance Markets: An Exaggerated Threat, 113 YALE L.J. 1223,1224 (2004) (showing that such death spirals are quite rare and that, in many cases, adverse selection is itself uncommon). In a recent update and extension of this article, Siegelman and Cohen find more mixed evidence of adverse selection in insurance markets, concluding that the phenomenon varies substantially across different lines of insurance and even within particular insurance lines. Alma Cohen \& Peter Siegelman, Testing for Adverse Selection in Insurance Markets, 77 J. RISK \& INS. 39 (2010).

17 Seth J. Chandler, Visualizing Adverse Selection: An Economic Approach to the Law of Insurance Underwriting, 8 CONN. INS. L.J. 435 (2002) (using computer modeling to show the extent to which adverse selection depends on numerous factors in the underlying insurance market).

${ }^{18}$ See Hoy \& Ruse, supra note 2, at 249-69; see also Chandler, supra note17, at 498 (making similar point by noting that homogeneity of risks in the underlying pool decreases the prospect of adverse selection, whereas heterogeneity increases this risk).

${ }^{19}$ This result is predicted by the Wilson Foresight model. In the classic Rothschild-Stiglitz model, there is actually no equilibrium when the number of high risk individuals is sufficiently low, because firms in that model do not exhibit foresight about future risks. They consequently attempt to generate a separating equilibrium in a manner that ultimately proves unprofitable. Anticipating this result, carriers in the Wilson Foresight do not attempt to disrupt the pooling equilibrium. See Charles Wilson, A Model of Insurance Markets with Incomplete Information, 16 J. ECON. THEORY 167 (1977).
} 
insurers would choose to not discriminate against the small number of high-risk individuals because the costs of doing so outweigh the benefits. ${ }^{20}$

Second, adverse selection is less likely to result from restrictions on risk classification when the expected costs of policyholders possessing that forbidden characteristic are only slightly higher than the expected costs of other policyholders. ${ }^{21}$ For instance, if men are only $1 \%$ more likely to be in car accidents than women, then legal restrictions on the capacity of auto insurers to discriminate on the basis of gender will be unlikely to generate substantial adverse selection. The explanation for this effect is the same as above: the impact of such laws on the premiums charged to "low-risks" will be limited. Consequently, relatively few low-risks will drop coverage and the impact of those that do will have minimal feedback effects. ${ }^{22}$

Third, risk-classification regulation is not likely to produce adverse selection when the purchase of minimum insurance policies is legally mandated. ${ }^{23}$ In these settings, low-risk individuals are legally compelled to remain within the insurance pool and cross-subsidize high-risk individuals. ${ }^{24}$ Prominent examples of laws requiring individuals to purchase insurance include automobile liability insurance and health insurance under the Affordable Care Act.

Fourth, adverse selection is unlikely to result from legal restrictions imposed on insurers' risk-classification practices when policyholder demand for insurance is relatively inelastic. In such cases, policyholders will tend not to drop out of the insurance market notwithstanding increases in the price of coverage caused by

\footnotetext{
${ }^{20}$ See supra Part I.B.7.

${ }^{21}$ Does Hoy make this point? If not, is this point in the literature at all? [Find cites]

${ }^{22}$ When the use of the characteristic has only minimal effects, of course, the insurers are less likely to use the characteristic in the first place, which means that the benefits of risk-classification restrictions are likely to be low.

${ }^{23}$ See, e.g., Baker, infra note 35, at 380.

${ }^{24}$ Significantly, this strategy represents the core explanation for the "individual mandate" in the Affordable Care Act, which compels most individuals to purchase "minimum essential coverage." Patient Protection and Affordable Care Act, § 1501(a), 42 U.S.C.A. § 18091 (West 2010); Id. 26 U.S.C.A. § 5000A. However, using an individual mandate or similar tool to combat adverse selection poses several complications. Such a system must be designed to police the minimum coverage floor effectively so that carriers cannot "classify by design" by offering stripped-down coverage to low-risk policyholders. It also must preclude carriers from classifying by design in other ways, such as by offering additional coverage that affirmatively appeals only to low-risk individuals. See, e.g., Amy Monahan \& Daniel Schwarcz, Will Employers Undermine Health Care Reform By Dumping Sick Employees, 97 VA. L. REV. 125, 158-62 (2011) (describing specific strategies by which employers complying with the PPACA may still be able to "dump" high-risk employees on to insurance exchanges but continue to cover low-risk employees). Finally, it must limit the capacity of carriers to design their marketing and sales strategies to target presumptively low-risk individuals. Id.
} 
risk-classification regulation. Inelastic demand is a general phenomenon that can be attributable to a variety of factors. For instance, it is more likely in settings where minimal levels of insurance are practically required, as in the case of homeowners insurance, which mortgagees generally require as a condition of a loan. ${ }^{25}$ Alternatively, demand may be more inelastic where the cost of insurance can be largely passed on to others. Thus, doctor demand for medical malpractice insurance may be inelastic if premium costs are principally borne by patients and their health insurers. ${ }^{26}$ And, of course, inelastic demand may simply reflect the fact that individuals are very risk averse. ${ }^{27}$

Fifth, risk-classification restrictions are less likely to generate adverse selection when high-risk policyholders cannot over-insure. ${ }^{28}$ In some settings, most notably life insurance, insurance coverage is non-exclusive, meaning that individuals can own multiple different policies and the benefits owed under one policy are not impacted by the existence of other policies. ${ }^{29}$ In these cases, standard requirements that individuals insure only up to their economically insurable interest may not effectively restrict the capacity of policyholders to enjoy

\footnotetext{
${ }^{25}$ Daniel Schwarcz, Reevaluating Standardized Insurance Policies, 78 U. CHI. L. REV. 1263, 1320 (2011).

${ }^{26}$ See Baker, infra note35, at 381; Mark Geistfeld, Legal Ambiguity, Liability Insurance, and Tort Reform, 60 DePAUl L. REV. 539 (2011).

${ }^{27}$ See Chandler, supra note17.One special case of inelastic demand, and thus decreased adverse selection risk, may occur in settings where individuals face substantial "classification risk," or what we call here "insurability risk." Insurability risk reflects the prospect that a policyholder's future premiums will increase or that coverage will become unavailable as a result of insurers' classification efforts. Although the term classification risk is used in the literature, see, for example, Pierre-André Chiappori, Econometric Models of Insurance under Asymmetric Information, in HANDBOOK OF INSURANCE 365, 365-94 (G. Dionne, ed., 2000), a more accurate term might be "insurability risk," since the worry is that an individual will be classified as uninsurable. Chandler focuses on the prospect that an individual will not be able to secure health insurance after the occurrence of a health event. But this issue is more general, and occurs in any insurance market where policyholders retain some classification risk as a result of loss, such as homeowners and auto insurance. Although the term classification risk is used in the literature, see, for example, Pierre-André Chiappori, Econometric Models of Insurance under Asymmetric Information, in HANDBOOK OF INSURANCE 365, 365-94 (G. Dionne, ed., 2000), a more accurate term might be "insurability risk," since the worry is that an individual will be classified as uninsurable. Chandler focuses on the prospect that an individual will not be able to secure health insurance after the occurrence of a health event. But this issue is more general, and occurs in any insurance market where policyholders retain some classification risk as a result of loss, such as homeowners and auto insurance.

${ }^{28}$ Hoy \& Ruse, supra note 2; Chapter 6. See Hoy \& Polborn, , at 235-252 ("The fundamental difference between life insurance and other insurance policies is, from an institutional point of view, that individuals can buy life insurance from as many companies as they want and therefore price-quantity contracts are not a feasible means against adverse selection; insurance companies can only quote a uniform price for all life insurance contracts. A second important difference between life insurance and other insurance is that there is no natural choice for the size of loss.").

${ }^{29}$ In most insurance contexts, policies contain coordination of benefits or "other insurance" provisions, which prevent a policyholder from recovering under multiple policies in a way that would improve the policyholder's financial condition as a result of the loss.
} 
a windfall in the event of a loss. ${ }^{30}$ For this reason, life insurance policyholders can effectively multiply the impact of their high-risk status on the pool, resulting in low-risk individuals being forced to shoulder a larger burden as a result of riskclassification restrictions. ${ }^{31}$

Sixth, the risk of adverse selection is smaller when a secondary market for insurance policies does not exist, a factor whose importance has seemingly escaped attention in the risk-classification literature. In life insurance and annuity markets policyholders can, and frequently do, sell their policies to investors. ${ }^{32}$ These secondary markets increase the risk of adverse selection by allowing high-risk individuals not merely to purchase a policy with an expected net benefit - the fifth advantage mentioned above - but instead they allow such individuals to purchase a policy with an immediate guaranteed profit. An individual with a genetic predisposition need merely purchase life insurance coverage and then sell this coverage to a third-party investor, who will pay some portion of the expected recovery to the policyholder in return for becoming the policy owner. While individuals have an incentive to hide their genetic defects from insurers, they have the opposite incentive when selling policies to third-party investors: the sooner the policyholder is to die, the more investors will be willing to pay for the policy. ${ }^{33}$ Not only do secondary markets increase the prospect of adverse selection by transforming expected values into assured values, they also allow high-risk individuals to benefit personally from their life insurance products. Without such markets, high-risk individuals could only benefit their heirs by purchasing additional insurance, which might limit the adverse selection risk. ${ }^{34}$

\footnotetext{
${ }^{30}$ At least when policyholders do not face any financial constraints on purchasing excess coverage. See Chandler, supra note17, at 454-55 (noting that some insurance is sufficiently expensive that even if policyholders were legally entitled to over-insure, many would be unable to do so because of liquidity constraints).

${ }^{31}$ Life insurers do have ways of limiting over-insurance of this sort. In their applications, they usually ask whether the applicant already has life insurance coverage and, if so, how much and with what insurer. Presumably the insurer considering the application takes into account the problem of over-insuring, and its implications for adverse selection and moral hazard, when deciding whether to issue a policy to such an applicant.

${ }^{32}$ See generally [Find cites]

${ }^{33}$ Risk classification rules that would prevent investors from asking about individuals' genetic makeup cannot prevent such transactions because these rules would not stop high-risk policyholders from volunteering information about their genetic predispositions.

${ }^{34}$ One potentially interesting twist here is that by over insuring and selling a policy to investors, an individual could potentially buy better medical care that may eventually save their lives. This possibility may tend to work against the risk of adverse selection. [Find cites]
} 
Seventh, product design can substantially impact the risk of adverse selection. In some cases, product design can counteract the risk of regulatory adverse selection. One setting where this is possible is when policyholders typically learn whether they are high-risk at some point after they have the opportunity to purchase coverage, as may occur with health status or genetic predispositions (as opposed to race or gender). In these cases, policyholders who discover they are low risk can drop coverage, leaving behind a disproportionately high-risk pool. Insurers can counteract this threat through effective policy design, such as by requiring policyholders to pre-pay for future coverage, so that they forfeit these payments if they leave the insurance pool once they discover they are low risk. ${ }^{35}$ In other cases, though, product design can increase the risk of regulatory adverse selection. Particularly in life and health insurance markets, for instance, insurers cannot cancel an insured's policy once the statutorily prescribed incontestability period has run, except for extraordinary reasons - such as proof of outright fraud. The same is not true of other types of insurance. ${ }^{36}$ This fact raises the value to life and health insurance applicants of engaging in adverse selection.

Eighth, regulatory restrictions on risk classification are more likely to produce adverse selection to the extent that policyholders both know about their own classification status and appreciate its link to risk. ${ }^{37}$ Where these conditions are not met, regulatory restrictions on insurer risk classification will not create information asymmetries between policyholders and insurers, and thus cannot generate adverse selection. ${ }^{38}$ For instance, regulatory prohibitions on the use of genetic composition will not tend to create adverse selection if policyholders are not themselves aware of their own genetic composition or fail to appreciate the connection between their genetic makeup and their risk levels.

\section{Fairness and Socially Suspect Characteristics}

\footnotetext{
${ }^{35}$ This is the strategy that level-premium life and disability insurance policies take, as they effectively require pre-payment of premiums in the early stages of life before many policyholders learn their risk status based on health developments. See Tom Baker, Containing the Promise of Insurance: Adverse Selection and Risk Classification, 9 CONN. INS. L.J. 371, 379-83 (2003).

${ }^{36}$ An insurer that sells individually underwritten auto or non-auto liability and property policies can cancel policies or decline to renew when the policy comes up for renewal. See Robert JeRRY, Understanding INSURANCE LAW.

${ }^{37}$ See Cohen \& Siegeleman, supra note 16.

${ }^{38}$ See id.
} 
Any type of discrimination can pose fairness problems to the extent that it trades on individual characteristics that are socially suspect. Policyholder characteristics can be deemed socially suspect for two related reasons. ${ }^{39}$ First, insurers' use of certain risk characteristics may reinforce or perpetuate broader social inequalities by making insurance less available or more expensive to historically disadvantaged groups. ${ }^{40}$ For instance, insurers who charged more to immigrant drivers would thereby perpetuate preexisting inequalities in this country. Second, risk-classification schemes may be socially suspect because they reflect, or arise out of, preexisting social inequalities and thus cause some sort of expressive harm, even though they do not penalize with higher rates members of groups who are traditionally disadvantaged. As an example, we might object to an insurer who announced that it was willing to sell annuities at better rates to African-Americans because they tend to have a shorter life span. Unlike the first example, this objection might persist even though the traditionally disadvantaged group is made better off as a result of the insurer classification scheme. Here the problem is not that a traditionally disadvantaged group is further harmer, but that the risk-classification scheme stereotypes, or expresses an inappropriate attitude toward the value of equal treatment. ${ }^{41}$

In many cases, of course, both types of argument can be deployed to label a classification scheme socially suspect. At times, though, classification schemes may be socially suspect based only on one of these two considerations. For instance, automobile insurance rating schemes have recently been criticized because they may result in lower-income individuals paying higher rates. ${ }^{42}$ This objection is principally based on the first type of argument: insurers' rating

\footnotetext{
${ }^{39}$ Abraham frames this category more broadly in his article, stating that a classification can be suspect for at least four reasons: (i) it is used improperly in other fields, (ii) it is not supported by sufficient data, (iii) it systematically works to the disadvantage of a particular group, or (iv) it perpetuates unfair disadvantages outside of the insurance system. In general, though, none of the first three explanations seem problematic unless they are coupled with the fourth. It is not, for instance, troubling that classification schemes systematically work to the disadvantage of individuals with bad driving records. Similarly, Abraham himself argues elsewhere in his article that mere inaccuracy is not, in itself, a basis for a fairness objection. See Abraham, supra note 2.

${ }^{40}$ Although often framed in terms of fairness, this argument can also be understood in economic terms as an externality argument: insurers impose harms on society at large by relying on certain suspect classifications.

${ }^{41}$ See generally Elizabeth S. Anderson \& Richard H. Pildes, Expressive Theories of Law: A General Restatement, 148 Penn. L. Rev. 1503 (2000) (“[E]xpressive theories tell actors—whether individuals, associations, or the State - to act in ways that express appropriate attitudes toward various substantive values.").

${ }^{42}$ Stephen Brobeck \& J. Robert Hunter, Consumer Federation of America, Lower-Income Households and the Auto Insurance Marketplace: Challenges and Opportunities, CONSUMERFED.ORG, Jan. 30, 2012, http://www.consumerfed.org/news/450.
} 
schemes are perpetuating income inequality by requiring lower income individuals to pay more for coverage. Indeed, it is hard to articulate an expressive harm from insurers' underwriting efforts because insurers generally do not explicitly rely on policyholder income in rating policies; instead, other classification measures simply have the impact of producing this result. By contrast, objections to the use of gender in life insurance may tend to rely exclusively on the second type of argument because gender-based premiums economically benefit women, whose expected life span is longer than men. Objections to such practices must therefore emphasize the expressive harm associated with reaffirming the relevance of gender-based social patterns and practices.

\section{Part II: Variation in State Insurance Anti-Discrimination Laws}

\section{A. The Empirical Approach: Coding State Anti-Discrimination Laws ${ }^{43}$}

To understand state law governing insurance discrimination, we investigated how each state (as well as Washington DC) regulates insurers' use of nine policyholder characteristics - race, religion, ethnicity, gender, age, genetic testing, credit score, sexual orientation, and zip code - across the five largest lines of insurance-life, health, disability, auto, and property/casualty. This produced 2295 sets of rules (9 traits times 5 lines of insurance times 51 jurisdictions), derived from state statutory, administrative, and judicial materials. ${ }^{44}$ For each state/characteristic/line combination, we then converted the applicable rules to one of six possible codes. These codes range along a continuum, from those that are least restrictive of insurers' underwriting decisions to those that are most restrictive. The entire continuum is reproduced below: ${ }^{45}$

Expressly Permit (-1) - The state has a statute expressly or impliedly permitting insurers to take the characteristic into account.

\footnotetext{
${ }^{43}$ This Article includes only a brief discussion of the empirical approach. For more details on how data was selected and coded, see Avraham, Logue \& Schwarcz, supra note 1.

44 Judicial decisions and administrative rulings rarely impacted the coding derived from state statutes. Surprisingly, out of the 2295 trait/line combinations ( 9 traits times 5 lines of insurance times 51 jurisdictions), only 16 total trait/line combinations were changed on this basis.

${ }^{45}$ We acknowledge that this continuum from permissive to stringent restrictions is neither perfectly continuous nor perfectly scaled, but it is the best that can be done given the nature of the data. It allows us to "see" the data in a way that makes it more accessible.
} 
No Law on Point (0) - The state laws are silent with respect to the particular characteristic.

General Restriction (1) - The state has a statute that generally prohibits "unfair discrimination," either across all lines of insurance or in some lines of insurance, but that statute does not provide any explanation as to what constitutes unfair discrimination and does not single out any particular trait for limitation.

Characteristic-Specific Weak Limitation (2) - The state has a statute that limits the use of a particular characteristic in either issuance, renewal, or cancellation.

Characteristic-Specific Strong Limitation (3) - The state has a statute that prohibits the use of a particular characteristic when the policy is either issued, renewed, or cancelled, or the state has a statute that limits but does not completely prohibit the use of a particular characteristic in rate-setting .

Characteristic-Specific Prohibition (4) - The state has a statute that expressly prohibits insurers from taking into account a specific characteristic in setting rates.

\section{B. An Overview of Variation in the Intensity of Risk Classification Regulation}

The data developed above reveal substantial variations in state insurance antidiscrimination laws across the nine characteristics that we investigated. This is easily seen in Chart I, which compares the average level of restrictiveness for each characteristic, for all lines of insurance and all states combined. ${ }^{46}$ Overall Chart 1 demonstrates that race, national origin, and religion are the most heavily regulated. All of these characteristics average more than a weak limitation ( 2 in our coding scheme), which means that each of these is specifically restricted in the law on insurance discrimination. The next most regulated characteristic is gender, followed by sexual orientation. Age is the least restricted, averaging less than a 1 in our cording scheme, meaning that state law only prohibits unfair discrimination

\footnotetext{
${ }^{46}$ For example, in Chart 1 the bar for race shows the average treatment for race across all 51 states and all five insurance lines. This is a total of 255 (51 x 5) laws that are, on average, slightly less than a strong limitation (a " 3 " on our coding scale).
} 
generically, but does not specify when or how age-based discrimination might be impermissible.

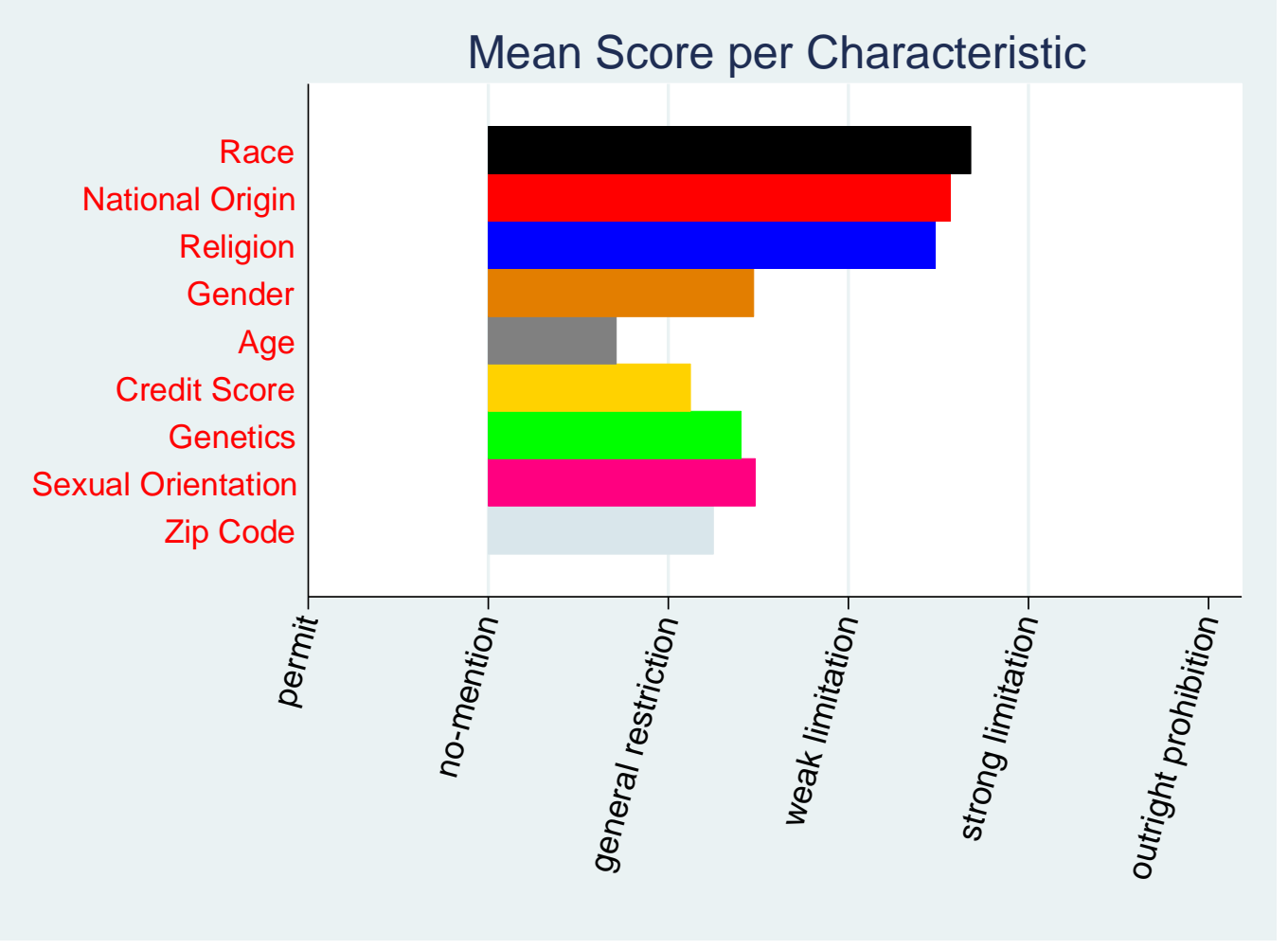

Chart 1

State insurance anti-discrimination laws vary not only across regulated characteristics, but also across insurance coverage lines. Chart 2 illustrates this cross-line variation in the intensity of risk classification regulation. It reports the average level of restrictiveness for each line of insurance, this time averaging together scores for all policyholder characteristics and all states. This value varies between just more than a "General Restriction" (or numerical score of 1) for disability insurance to just more than a Characteristic-Specific "Weak Limitation" (or numerical score of 2) for auto and property/casualty. Thus, our data suggest that state laws regulating risk-classification practices are the most restrictive in the auto and property/casualty insurance lines and the least restrictive for disability and 
life insurance lines, ${ }^{47}$ State anti-discrimination laws for health insurance fall in between these extremes.

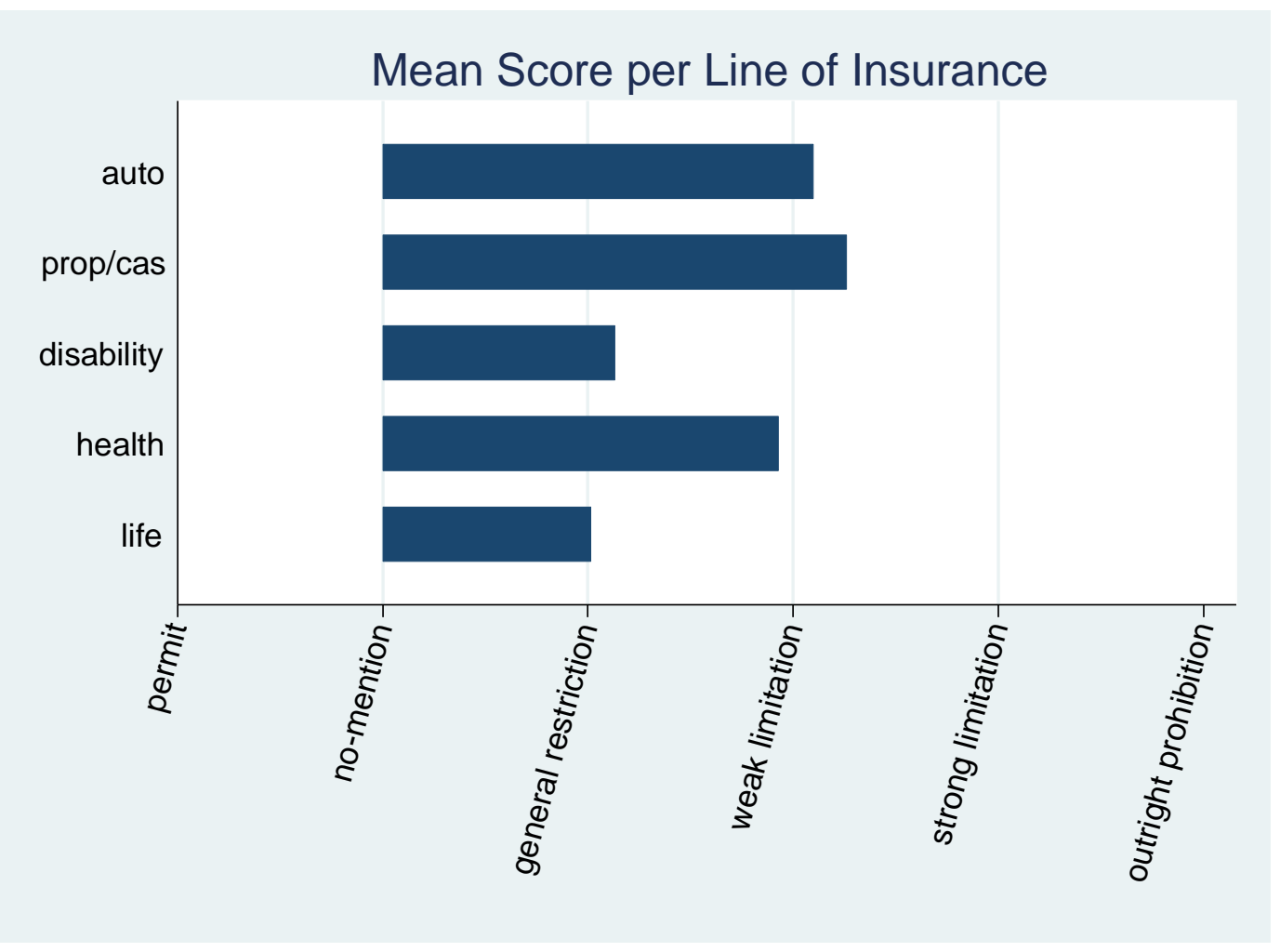

\section{Chart 2}

Chart 3, below, reports the restrictiveness of state risk-classification regulations by characteristic as well as by coverage line. It contains the same information as in Chart 2, but with the blue bar "removed" to expose the average scores across states for each line/characteristic combination.

\footnotetext{
${ }^{47}$ One possible explanation for the restrictiveness of each line of insurance is that states with general restriction statutes for a specific line of insurance may not have felt a need to pass stricter laws. However, as seen in Avraham et al, supra note [Anatomy Paper], this was not a relevant factor in explaining cross-line variations.
} 


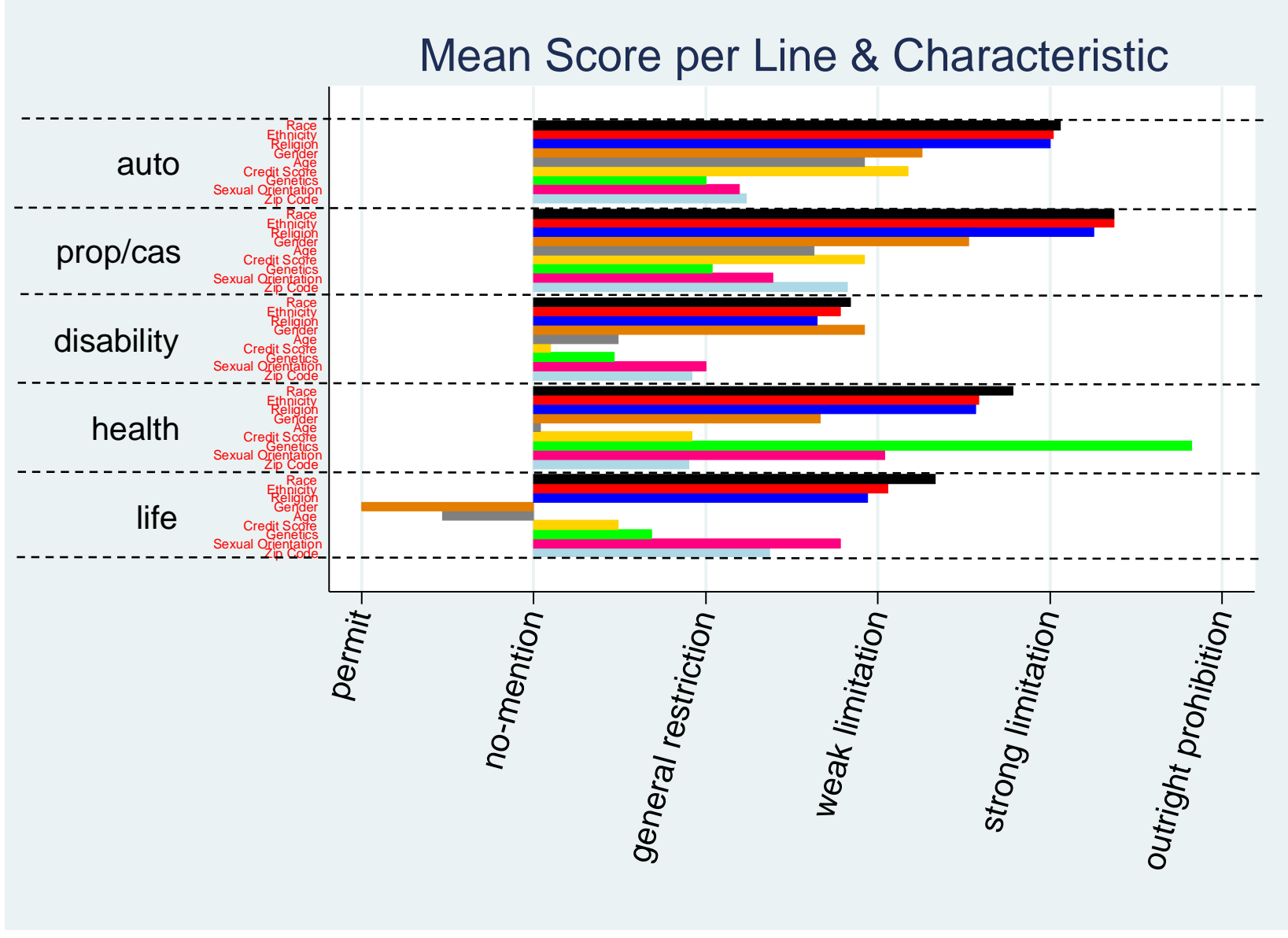

\section{Chart 3}

Chart 3 suggests that the similarities in risk classification restrictions in auto and property/casualty insurance extend beyond the similar aggregate measures reported in Chart 2. Both lines of insurance seem to have a very similar pattern of risk classification restrictions across different characteristics, as reflected in the similar patterns of data reported in the auto and property/casualty insurance entries in Chart III. A similar point can be made for health and life insurance, with the exception of genetics (the green bar), age (the gray bar) and gender (the brown line), which vary significantly in their treatment across these two lines of coverage. Disability insurance seems to stand out as unique in its pattern of risk classification restrictions.

Chart 3 also shows that the comparatively heavy regulation of race, national origin, and religion noted in Chart 1 exists across all lines of insurance. These characteristics (the top 3 bars-black, red, and blue) are almost always the most intensely restricted characteristics in every coverage line, with sometimes a full 
one-point difference between them and the next most restricted characteristic, namely gender. ${ }^{48}$

In addition to adding some nuance to the data reported in Charts 1 and 2, Chart 3 also reveals some interesting disparities in how individual policyholder characteristics are treated across different lines of coverage. Consider policyholder genetics, for instance, which is reported in the green bar. Chart 3 shows that 48 of the 51 jurisdictions completely prohibit the use of genetics for health insurance, giving genetics the highest overall restrictiveness score of any characteristic for a single line of insurance, even though in the other four lines the mean score for genetics is low. ${ }^{49}$ This near consensus among states regarding the use of genetic information in health insurance is reflected in the 2008 passage of the federal Genetic Information Non-Discrimination Act, which forbids the use of genetic information in health insurance. ${ }^{50}$

Genetics is not the only policyholder characteristic that is regulated differently across different lines of insurance. Chart 3 also shows that gender (the brown bar) is highly restricted in auto, property/casualty and disability insurance, but only weakly restricted in health and permitted by all states in life. ${ }^{51}$ Somewhat similarly, Chart 3 shows that credit score (the yellow bar) is more intensely restricted in automobile and property/casualty insurance than in disability, health, and life insurance. Finally, age (the dark gray bar) is also regulated quite different across different lines of insurance. In health and life insurance, age tends towards the "permitted" score, whereas age is regulated much more strongly (averaging a weak restriction) in property/casualty and auto insurance. ${ }^{52}$ These disparities in how individual policyholder characteristics are treated across different lines of

\footnotetext{
${ }^{48}$ The only exceptions are restrictions on genetic traits in health insurance underwriting and restrictions on gender in disability insurance. The "big three" phenomenon can also be seen when looking at the number of jurisdictions that completely prohibit the use of a characteristic across all five lines of insurance. Race ( 9 states), ethnicity ( 9 states), and religion (7 states), along with sexual orientation (5 states) and gender (one state), are the only characteristics that were banned in all five lines of insurance by a state. For more on this, see Avraham, Logue, \& Schwarcz, supra note 1, at _...

${ }^{49}$ New York is the only state which allows (with heavy restrictions) insurers to use genetic testing in health insurance. See N.Y. INS. LAW § 2615.

${ }^{50}$ Pub. L. No. 110-233 § 102(b)(1)(B) 122 Stat. 881 (2008). Under the Act genetic testing is defined to include family history of disease.

${ }^{51}$ As noted later, federal health care reform will prohibit this practice in health insurance starting in 2014.

${ }^{52}$ Chart 3 reveals that on average sexual orientation (pink) and zip code (light blue) are treated very similarly in all lines of insurance. They almost always fall around the score of "general restriction."
} 
coverage are explored more extensively below, where we attempt to explain them using our model.

In summary, there are wide variations in state regulation of insurers' risk classification practices. Across policyholder characteristics, the most restricted characteristics are race, ethnicity, and religion (the "big three"), and the most restrictive combination (outside of the big three) is genetics in health insurance. Across insurance lines, automobile insurance and property/casualty insurance are similarly regulated, and constituted the most restrictive lines of insurance. Health and life insurance are also similarly regulated with respect to permissible risk classification, with health being more restrictive. Finally, various individual policyholder characteristics, including genetics, gender, credit score, and age, are regulated very differently across different lines of coverage.

\section{Part III. Explaining Variation of Characteristic/Line Combinations}

This Part attempts to explain the variations described in Part II by reference to the three factors described in Part I. As described at the outset, our basic model suggests that state legislatures strike a balance between the efficiency and fairness considerations involved in insurance discrimination as follows:

a) The predictive property - State legislatures will be more likely to consider regulating (either by prohibiting or permitting) risk classification based on a characteristic (like age) if that characteristic has predictive value for policyholder risk. ${ }^{53}$

b) The illicit discrimination property-State legislatures will be more inclined to prohibit risk classification based on a characteristic (like age) to the extent that doing so would help combat (or appear to combat) illicit discrimination.

c) The adverse selection property - State legislatures will tend to allow risk classification to the extent that limiting such discrimination would be likely to trigger adverse selection.

\footnotetext{
${ }^{53}$ State legislatures therefore tend to not regulate risk classifications when insurers have anyway no economic incentives to do it because the characteristics convey no relevant information for that line of insurance. An example for that is sexual orientation in automobile insurance.
} 
These properties must be balanced against each other to determine the outcome of state laws.

Section A of this Part begins with the easiest task: explaining the broad patterns of cross-characteristics variation in the intensity of state insurance antidiscrimination law described above. Section B then attempts to explain the patterns of cross-line variation. Finally, Section C uses our proposed model to explain cross line variations in states' treatment of individual policyholder characteristics, including gender, age, and genetics.

\section{A. Explaining Cross Characteristic Variations}

The cross characteristic variation described in Chart 1 can largely be explained by the illicit discrimination prong of our model. First, the fact that race, national origin, and religion are the three most restricted characteristics is broadly consistent with social judgments that discrimination on the basis of these characteristics is socially suspect, as reflected in both federal anti-discrimination laws and Supreme Court precedent. Thus, federal antidiscrimination laws, like Title VII ${ }^{54}$ (banning employment discrimination) and Title VIII ${ }^{55}$ (banning discrimination in the sale or rental of housing), prohibit discrimination because of an individual's "race, color, religion... or national origin." Similarly, discrimination on the basis of race, national origin, and religion has long been subject to strict scrutiny under the Supreme Court's Equal Protection jurisprudence. $^{56}$

Correspondingly, gender - the next most heavily regulated characteristic in state insurance regulation - is subject to similar, though slightly less robust, federal anti-discrimination protections than the big three. Both Title VII and Title VIII prohibit discrimination on the basis of gender to the same extent that they prohibit discrimination on the basis of race, national origin, and religion. But gender only

\footnotetext{
5442 U.S.C.A. $\$ 2000 \mathrm{e}-2$.

5542 U.S.C.A. $\$ 3604$ (West).

${ }^{56}$ Miller v. Johnson, 515 U.S. 900, 904 (1995); Church of Lukumi Babalu Aye, Inc. v. Hialeah, 508 U.S. 520 ,

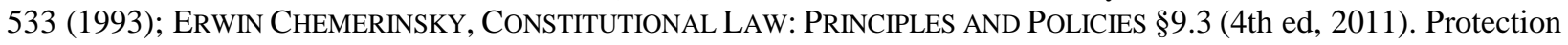
from religious discrimination has also been a part of the Constitution since our country's founding. U.S. CONST., AMEND. I.
} 
received an intermediate level of scrutiny under the Supreme Court's Equal Protection jurisprudence. ${ }^{57}$

The fact that sexual orientation is the next most restricted characteristic after gender is also broadly consistent with emerging norms about socially suspect characteristics. To be sure, discrimination on the basis of sexual orientation has not been recognized for protection by federal laws in the same way that race, religion, national origin, and gender have been. And while the Court has implied a willingness to protect gays and lesbians from discrimination, so far it has done so only using rational basis review. ${ }^{58}$ Moreover, gay rights have been enjoying greatly enhanced protections at the state level in recent years, with numerous states passing new laws in support of gay marriage ${ }^{59}$ and prohibiting discrimination on the basis of sexual orientation in areas like employment. ${ }^{60}$

Age is the least regulated characteristic in state insurance law, which is a little harder to understand based solely on the illicit discrimination prong of our model. On one hand, discrimination on the basis of age is only subject to rational basis review under Equal Protection analysis, ${ }^{61}$ and it is not protected under Title VII or Title VIII. On the other hand, though, the Age Discrimination in Employment Act provides basically the same protections for age as Title VII does for race, color, religion, sex, and national origin. ${ }^{62}$

\section{B. Explaining Cross Line Variations}

The broad patterns of cross-line variation in state insurance antidiscrimination law can largely be explained by our model, particularly the third prong - the adverse selection property. Recall that the auto and property/casualty insurance lines are the most heavily restricted by state anti-discrimination laws. This is consistent with the fact that these coverage lines are relatively less

\footnotetext{
${ }^{57}$ United States v. Virginia, 518 U.S. 515, 531 (1996) (“'[p]arties who seek to defend gender-based government action must demonstrate an 'exceedingly persuasive justification' for that action.").

${ }_{58}^{58}$ Id. at 808.

59 http://www.washingtonpost.com/blogs/the-fix/wp/2013/03/18/gay-marriage-support-hits-new-high-in-postabc-poll/ (showing 58\% of Americans support gay marriage).

${ }^{60} \mathrm{http}: / /$ www.gallup.com/poll/1651/gay-lesbian-rights.aspx (showing 89\% of Americans agree that homosexual men and women should have equal job opportunities, and 9 out of 10 Americans think there is already a federal law to ensure this).

${ }^{61}$ ERWin ChEMERINSKy, CONSTITUTIONAL LAW: PrinCIPLES AND POLICIES 802 (4th ed, 2011).

${ }^{62}$ See 29 U.S.C.A. $§ 623$ (West).
} 
susceptible to adverse selection than other lines of coverage, giving the state more leeway to prohibit discrimination without triggering adverse selection.

Auto and property/casualty insurance lines are relatively resistant to adverse selection because minimum coverage levels are generally legally or practically mandated in these lines. Automobile drivers, of course, are legally required to carry a minimum amount of liability insurance in virtually every state. They are also frequently required to purchase UIM coverage. Individuals who finance the purchase of a car, which is quite common, are also commonly required to maintain comprehensive and/or collision. Similarly, individuals who finance the purchase of a home, which is almost all homeowners, are required by their lenders to maintain minimum levels of homeowners insurance. Recall from Part I that when coverage is mandated, either de jure or de facto, the risk of adverse selection is smaller.

Just as the adverse selection property of our model can explain the relative strength of state anti-discrimination laws in auto and homeowners insurance, it can also explain the relative weakness of these laws in the context of life and disability insurance. That is because life and disability insurance are comparatively quite susceptible to regulatory adverse selection. This point is particularly compelling with respect to life insurance for three reasons. First, life insurance may be especially susceptible to adverse selection from asymmetric information because individuals can relatively easily over-insure their own lives by purchasing policies from several insurers. ${ }^{63}$ Second, there exists a robust secondary market for life insurance policies, allowing high-risk individuals to immediately profit with certainty from the purchase and the immediate sale of these policies when regulatory rules preclude accurate underwriting. Third, insurers cannot drop insureds in life insurance because their risk has changed. Life insureds' renewability of the policy is guaranteed until they die or decide to drop their coverage. Thus, every high-risk insured who makes it into the pool will stay there for long time.

${ }^{63}$ See Hoy \& Polborn, The Value of Genetic Information in the Life Insurance Market, 78 J. PuB. ECON. 235 (2000) ("The fundamental difference between life insurance and other insurance policies is, from an institutional point of view, that individuals can buy life insurance from as many companies as they want and therefore pricequantity contracts are not a feasible means against adverse selection; insurance companies can only quote a uniform price for all life insurance contracts. A second important difference between life insurance and other insurance is that there is no natural choice for the size of loss."). 
Adverse selection may also be a problem in the context of disability insurance, though this is less clear than in the case of life insurance. The peculiar risk of adverse selection in disability insurance stems from the fact that, relative to other lines of coverage, disability insurance claims are low frequency, but often involve large payouts. ${ }^{64}$ This means that a small number of high-risk individuals can substantially skew the prices that low-risk individuals pay. ${ }^{65}$

Finally, the risk of regulatory adverse selection also seems to provide a plausible explanation for the fact that state anti-discrimination laws in health insurance fall in between property/casualty and auto insurance, on one end, and life and disability insurance, on the other. This is because adverse selection concerns with respect to the type of discrimination we investigate - which does not include health-based discrimination - are quite nuanced in the health insurance context. On one hand, none of the special factors applicable to life insurance apply to health insurance markets: over-insurance is not possible, there are no secondary markets for policies, at least until recently insurers could drop high risk insureds, and substantial payouts are made on a comparatively large number of policyholders. Additionally, depending on state law, health insurance carriers (until very recently) could combat adverse selection through product design, for example by asking for applicants' medical history. ${ }^{66}$ Health insurance carriers also enjoy a unique ability to sell coverage on a group basis because the tax code confers substantial tax benefits on employer-sponsored coverage. ${ }^{67}$ Employer-sponsored coverage combats the risk of adverse selection without any underwriting because employees

\footnotetext{
${ }^{64}$ American Academy of Actuaries, The Use of Genetic Information in Disability Income and Long-Term Care Insurance, at 2 (2002), available at http://www.actuary.org/pdf/health/genetic_25apr02.pdf.

${ }^{65}$ This corresponds to the first adverse selection argument that there are a small number of high-risk individuals.

${ }^{66}$ The extent to which life and disability insurance underwriters also use product design to combat adverse selection is unclear. To the extent that they do not request information about one's family history of genetic disease, the rationale for this is also unclear. What we do know is that requesting a family history of diseases is the norm in health insurance underwriting.

${ }^{67}$ Specifically, federal tax laws allow the full value of employer-provided health insurance to be excluded from employees' income for purposes of calculating their income tax liability. 26 U.S.C. $\S 106$. While life and disability insurance are also frequently sold on a group basis, there is less bias towards group markets in these contexts, principally because of the absence of comparable tax subsidies. Approximately $50 \%$ of life insurance policies are sold through employers, and approximately $50 \%$ are sold through the individual market, though policies sold in the individual market tend to be larger. Cheryll D. Retzloff, Person-Level Trends in U.S. Life Insurance Ownership, LIMRA.COM, at 12 (Mar. 2011) available at http://media.hbwinc.com/pdf/Person_Level_Trends_in_U.S._Life_Insurance_Ownership_2011.pdf. A substantial majority of private health insurance is sold through employers. See David A. Hyman \& Mark Hall, Two Cheers for Employment-Based Health Insurance, 2 Yale J. Health Pol'y L. \& Ethics 23, 30 (2001).
} 
are relatively heterogeneous with respect to most health-related factors, and definitely with respect to their genetic predisposition to illness. ${ }^{68}$

On the other hand, the adverse selection prong of our model cannot fully explain the treatment of health insurance, as regulatory adverse selection caused by at least some of the anti-discrimination rules we isolate is a very real risk in health insurance for two reasons. First, and most importantly, the expected costs of high risk policyholders in the context of some anti-discrimination rules - particularly age and gender - can be substantially larger than the expected costs of low-risk individuals. $^{69}$ Second, there are a potentially large number of people who constitute high-risk individuals in this context. ${ }^{70}$ All of this is consistent with the fact that the ACA will limit discrimination on the basis of age and prohibit discrimination on the basis of gender starting in 2014. That is because the ACA also contains and individual mandate and substantial tax subsidies, both of which were specifically designed to limit the risk of adverse selection.

The middling level of state anti-discrimination law in health insurance becomes more understandable, though, when the illicit discrimination prong is added back in to the analysis. Concerns about illicit discrimination are stronger in health insurance than in any other line of coverage, as many view adequate health insurance to be a "right," whereas few make similar arguments for other forms of coverage. $^{71}$ As such, even if adverse selection concerns were as substantial in health insurance as they are in life and disability, thus tending to lead to less state anti-discrimination regulation, the illicit discrimination prong would tend to push in the opposite direction, promoting stronger anti-discrimination laws. The result would be a middling level of protection, precisely what we observe.

\footnotetext{
${ }^{68}$ See Mark Hall \& David Hyman, Two Cheers for Employer Sponsored Coverage, 2 YalE J. Health PoL'Y L. \& ETHICS 23 (2002).

${ }^{69}$ This is factor 2 discussed in Part I.A.

70 This is factor 1 discussed in Part I.A.

${ }^{71}$ See Nowlan, infra note 78 ("[A] clear distinction exists between economic and ethical considerations involved in underwriting health insurance and those that apply to life insurance. Life insurance in this country is not a societal right, although everyone is potentially eligible for limited survivorship benefits through social security."). But see Susan M. Wolf \& Jeffrey P. Kahn, Genetic Testing and the Future of Disability Insurance: Ethics, Law \& Policy, J.L. MED. \& ETHICS 6 (2007) (noting that the difference in the laws may be attributable to the difference in "social importance" that people place on health insurance over life and disability insurance, but arguing that genetic information should be banned from disability insurance as well).
} 


\section{Explaining Particular Cross line/Cross Characteristic Combinations}

Our model does a relatively good job of explaining the broad trends in crosscharacteristic variation and cross line variation that we observe. In this section, we show that the model also provides relatively good explanations for many of the more specific patterns of state antidiscrimination law, wherein variation exists in the treatment of individual policyholder characteristics are treated across different lines of coverage.

\section{Cross-Line Treatment of Genetics}

As noted in Part II, and more specifically illustrated in Chart 4 below, there is tremendous variation in the treatment of genetics across policy lines. This variation, moreover, does not follow the more general trends in cross-line variation: most notably, health insurance is much more strongly regulated than the other lines. In fact, the use of genetic information in health insurance underwriting is the most restrictive trait in our study. By contrast, Chart 4 shows that there is very little regulation of genetics in the other lines of insurance. ${ }^{72}$ In fact, many states go so far as to explicitly permit the use of genetic information in other lines of insurance ( $a$ " -1 " in our coding scheme). This can be seen in life insurance, and to a greater degree in disability insurance, which are regulated similarly with respect to genetics. ${ }^{73}$ The Genetic Information Nondiscrimination Act (GINA) mirrors this result at the federal level, prohibiting health insurers (and employers) from using individuals' genetic information, but leaving other forms of insurance unregulated with respect to genetic discrimination.

\footnotetext{
${ }^{72} \mathrm{New}$ York is the only state to permit the use of genetic testing in health insurance, making it an outlier. New York is not even consistent, also permitting genetics in life and disability insurance but restricting the use of genetics in auto and property/casualty.

${ }^{73}$ The main visual difference between life and disability insurance in Chart 4 is that while there are several states which do not mention anything about the usage of genetic test in disability insurance (score 0 ), there are no such states in life insurance, an as more states have the score of 1 (general restriction). That is not a major difference.
} 


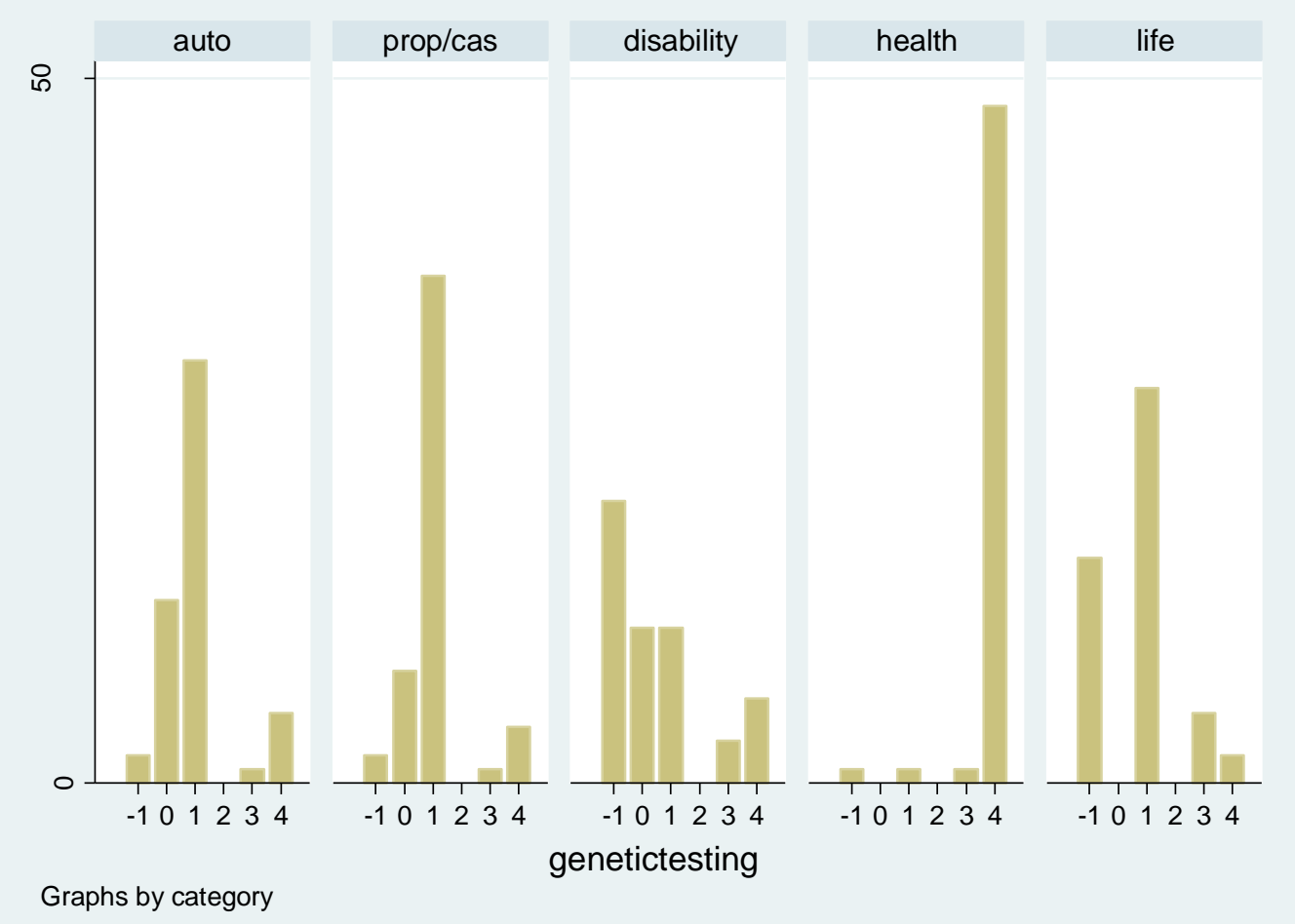

Chart 4: Distribution of States' Scores for Genetic Testing, by Insurance Line

Our model does a relatively good job of explaining these patterns. ${ }^{74}$ First, consider the treatment of genetic information in automobile and property/casualty insurance, which is usually restricted under states' general restriction laws (category 1). In addition, many states do not even mention genetic information in their laws, and only two states expressly permit discrimination based on genetic information. These trends are consistent with prong 1 of our model, reflecting the fact that genetic testing does not (at least yet) seem to provide information that is predictive of expected losses with respect to auto and property/casualty insurance. As the first prong of our model predicts, legislatures are unlikely to act when insurance companies are not using, and are not likely to use, a specific characteristic in their underwriting decisions.

The observed patterns in life and health insurance are also consistent with our model. In these domains, where genetics is indeed quite predictive of risk, the

\footnotetext{
${ }^{74}$ For other attempts to explain these patterns, see Michael Hoy \& Mattias Polborn, The Value of Genetic Information in the Life Insurance Market, J. PUB. ECON. 78 (2000); Wolf \& Kan, supra note 71.
} 
illicit discrimination prong of our model becomes central. Genetic discrimination in the context of health, life, and disability insurance immediately evokes Nazi Germany and its obsession with promoting the reproduction of more "genetically desired" people and eliminating "genetically defective" individuals. Under this worldview, Nazis first forced those with Huntington disease to be sterilized and later murdered them in extermination facilities. ${ }^{75}$ The United States also has a history of forced sterilization based on supposed genetic defects. ${ }^{76}$ This history has led to broad social protections for those with genetic conditions, and suggests that in the health, life, and disability insurance domain, insurers' use of genetics would raise strong concerns about illicit discrimination on the basis of socially suspect categories. $^{77}$

At the same time, the adverse selection prong of our model is also relevant to assessing prohibitions on insurers' use of genetic information. This fact largely explains why genetic discrimination is treated so differently in health insurance, on the one hand, and life and disability insurance, on the other hand. As was explained in the previous section on the intensity of regulation, life and disability insurance markets are generally more susceptible to adverse selection than health insurance markets (at least with respect to the policyholder characteristics we studied). As such, while the illicit discrimination prong overwhelms the adverse selection prong in health insurance, it is unable to do so in life and disability insurance, where the efficiency argument for allowing the use of genetic information is stronger.

This argument is enhanced by the fact that adverse selection concerns about genetic information in the health insurance context are relatively muted for health insurance policies purchased in individual markets. Such policies are often only in

\footnotetext{
${ }^{75}$ Thomas Lemke, "A Slap in the Face. An exploratory study of genetic discrimination in Germany", Genomcis, Society and Policy. Vol 5(2) pp22-39 (2009).

${ }^{76}$ Genetic Information Nondiscrimination Act of 2008, PL 110-233, May 21, 2008, 122 Stat 881.

${ }^{77}$ Standing on their own, illicit discrimination arguments are not persuasive in explaining the differential treatment of genetic discrimination in health, on the one hand, and life and disability on the other. One might argue that genetic risk should be prohibited as a factor for obtaining health insurance based upon the view that adequate health insurance is a "right." While this argument may contribute to the differences in treatment of genetic information across insurance lines, the fact that gender and age are allowed to be taken into account in health insurance (as we show below), suggests that the economic impact of adverse selection is a more powerful explanation. In fact, the Genetic Information Nondiscrimination Act specifically clarifies that "[t]he term 'genetic information' shall not include information about the sex or age of any individual." Genetic Information Nondiscrimination Act of 2008, PL 110-233, May 21, 2008, 122 Stat 881.
} 
force for a short time. Yet genetic predisposition to illness represents a long-term, and typically a probabilistic threat. For these reasons health insurers often focus on the short-terms risks of their policyholders and may not have an incentive to attempt to identify such long-term risks. ${ }^{78}$

\section{Cross-Line Treatment of Gender}

State laws also vary dramatically across coverage lines in the extent to which they allow insurers to take into account gender in classifying policyholders. This is most vividly demonstrated in the domain of health insurance. As Chart 5 reveals, 18 jurisdictions expressly permit the use of gender in health insurance, and 28 jurisdictions strongly limit or expressly prohibit its use. Gender is such a prominent issue for health insurance that every jurisdiction has addressed it in one way or another - either with a general or a specific statute; in other words, there are no entries in the "no-law-on-point" column of Chart 5. Starting in 2014, the Affordable Care Act will prohibit insurers from charging higher rates due to gender in the individual and small group insurance markets. ${ }^{79}$ Not surprisingly, the treatment of gender in life insurance is similarly fractured. ${ }^{80}$

${ }^{78}$ William Nowlan, A Rational View of Insurance and Discrimination, 297 SCIENCE 195 (2002).

79 Key Features of the Affordable Care Act, By Year, HEALTHCARE.GOV http://www.healthcare.gov/law/timeline/full.html\#2014 (last visited Aug. 17, 2012). Irrespective of whether this approach is "correct" Chart 5 suggests that the Affordable Care Act can be defended on the basis that it establishes a national policy on the issue. Even though states generally have autonomy to make their own decisions about various issues, the federal government has long played a central role in regulating discrimination on the basis of gender. Cite Title VII or IX

${ }^{80}$ Chart 5 shows that 21 jurisdictions permit its use compared with 19 jurisdictions strongly limiting it and two states, Montana and North Carolina, prohibiting it. The remaining 9 jurisdictions restrict its use. As with health insurance, every jurisdiction has some opinion on how gender should be treated, as there are not any "no-law-onpoint" entries. And, as with health insurance, these differences raise questions not just about the "correct" approach, but also about whether this type of variation among states should be allowed. 


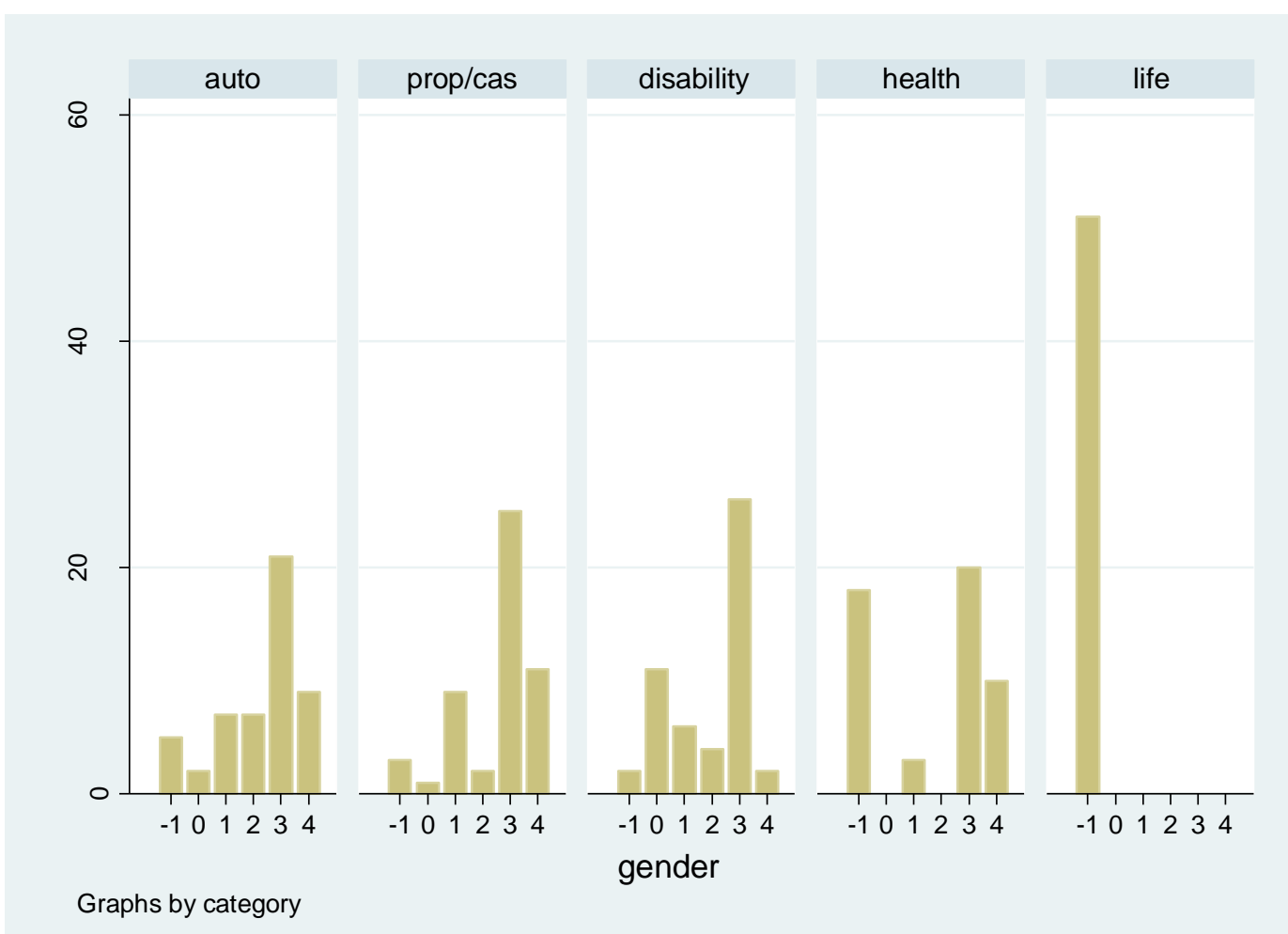

Chart 5: Distribution of States' Scores for Gender, by Insurance Line

The use of gender is both less polarized and more restricted in the other three lines of insurance. For the property/casualty line, most states are on the restrictive side of the chart, with twenty-five strongly limiting its use. ${ }^{81}$ Not surprisingly, state laws display a similar pattern with respect to auto insurance. ${ }^{82}$ Disability insurance is also restrictive with only Washington expressly permitting the use of gender and twenty-six strongly limiting it.

The cross-line variation in the treatment of gender substantially matches the more general cross-line variation described in Chart 2. Both overall and with gender specifically, auto and property/casualty insurance received the most restrictive scores. Similarly, life insurance received the lowest score overall and with gender as well. The only lines for which gender differed from the average of all nine characteristics were health and disability. As seen in Chart 2, health insurance on average is treated more restrictively than disability insurance, but

\footnotetext{
${ }^{81}$ Only Maryland expressly permits the use of gender and Kansas has no law on point.

82 Only four states (California, Delaware, Louisiana, and Maryland) permit gender's use and twenty-two strongly limit it.
} 
with gender the opposite is true-states are more restrictive with disability insurance and less restrictive with health insurance.

All of this suggests that the broad explanations for cross-line variation discussed above - which focus predominantly on adverse selection - can also explain the more specific pattern of cross line variation found with respect to gender. Indeed, when looking at gender and life insurance, the differences between men and women in mortality risks are more important than is often assumed. Although the average difference in life expectancy between men and women is only several years, the difference in one's chance of dying in a given year varies greatly by gender. ${ }^{83}$ Similarly, substantial differences exist in the expected health care costs of men and women due to the costs of child bearing, meaning that adverse selection also a substantial risk when gender-based classification is prohibited with respect to health insurance. ${ }^{84}$ While troubling on fairness grounds, this makes sense because it prevents an individual from waiting until she intends to become pregnant before enrolling in an insurance plan. If insurers cannot discriminate on the basis of gender they may have to charge higher prices to men relative to their (assigned) risk, causing them to drop out of the risk pool. ${ }^{85}$ This explanation is consistent with the ACA's ban on gender-based underwriting, as the risk of adverse selection is largely counteracted by the incorporation of the individual mandate in the statute. ${ }^{86}$ By contrast, adverse selection is not a substantial risk when state laws prohibit insurers from using gender in auto or property/casualty insurance. In addition to coverage mandates and lender requirements (which are explained above), this is because gender does not appear to correlate strongly with risk in property/casualty insurance, a fact that both limits the practical effect of the law as well as the risk of adverse selection. In the automobile insurance context, where gender may arguably play a role, the expected differences in risk between men and women, once other policyholder characteristics are taken into account, may be relatively small.

\footnotetext{
${ }^{83}$ But see Mary W. Gray \& Sana F. Shtasel, Insurers Are Surviving Without Sex, 71 A.B.A. J. 89 (1985).

${ }^{84}$ One way that insurance companies prevent adverse selection in the individual market is by not including coverage for maternity costs. STILl NOWHERE to TURN: INSURANCE COMPANIES TREAT WOMEN LIKE A PREEXISTING CONDITION, NATIONAL WOMEN's LAW CENTER 3 (2009) (finding that 87\% of health plans in the individual market available to a 30 -year-old woman do not provide maternity coverage).

${ }^{85}$ Interestingly, this might have the opposite effect for women with no plans to become pregnant. Such women would face an even greater discrepancy between their true risks and their premiums if insurers charged only women for the expected costs of child birth than if they spread this risk among women and men.

${ }^{86}$ See supra Part I.
} 
To the extent that the cross line variation for gender does not match the broader patterns of cross-line variation described above, they are nonetheless consistent with our model. In particular, the fact that health insurance is more strongly regulated than disability insurance likely stems from the first prong of our model: gender has a clear predictive value in life and health insurance, and therefore it is clear why no state has left gender unregulated in these lines of insurance. In contrast, it is not clear that gender has a predictive value in disability insurance, which may explain why 10 states have left it unregulated. Prong 1 in the specific context of gender thus alters the usual ordering of health and disability insurance.

Our model is also consistent with the fact that gender is so lightly regulated with respect to life insurance. Illicit discrimination arguments against genderbased discrimination in the life insurance context are comparatively less compelling than in other lines. First, while gender-based discrimination increases women's premiums for annuities, it decreases women's premiums for life insurance products, so the net actual effect is likely to be small and may even be null. ${ }^{87}$ Second, the ultimate beneficiaries of life insurance products are frequently the spouse or children of the person insured therefore, even if discrimination were prohibited and one gender were forced to pay systematically higher premiums than the other gender, it is not clear that the incidence of such a premium differential would be borne systematically by one gender or the other. Both of these points mean that discrimination does not systematically harm or help women, and thus that any fairness-based argument trading on the notion that gender is a socially suspect classification category is substantially weakened.

\section{Cross-Line Treatment of Age}

States' regulation of age-based classifications also varies substantially across insurance lines, as reflected in Chart 6. On one hand, state laws are strongly permissive with respect to insurer use of age in life and health insurance. ${ }^{88}$ In life insurance 39 jurisdictions permit its use and none specifically limit or prohibit it. In health insurance, 36 jurisdictions - more than two-thirds - permit the use of age

\footnotetext{
${ }^{87}$ Most states treat traditional life insurance and annuities similarly in their risk classification regulations.

${ }^{88}$ In fact, Chart 3 showed that age is the only characteristic that, on average, leans towards being expressly permitted for any line of coverage. This is true for both health insurance and life insurance.
} 
by insurance companies, while only 11 strongly limit its use. ${ }^{89}$ Starting in 2014 federal healthcare reform will limit differentials in premiums based on age to no more than a ratio of 3 to $1 .^{90}$ On the other hand, age is more restricted in auto and property/casualty lines of insurance. Most states are on the restrictive side of the chart in these lines, with twenty-five having only general unfair discrimination rules applying to age. ${ }^{91}$ Finally, most jurisdictions do not mention age in their disability insurance laws, or only provide a general restriction. ${ }^{92}$ Overall, disability insurance is another non-restrictive line of insurance with the unique fact that most states (twenty six) do not mention anything at all.

\footnotetext{
${ }^{89}$ Notably, eleven jurisdictions strongly limit the use of age in health insurance underwriting decisions. See, e.g., California, Idaho, Illinois, Florida, Maine, Massachusetts, Michigan, Minnesota, Pennsylvania and Vermont.

${ }^{90}$ Patient Protection and Affordable Care Act , § 2701(a)(1)(A)(iii).

${ }^{91}$ In auto insurance, only Delaware, Louisiana, and Michigan permit the use of age, five others have no-law-onpoint, and the rest are roughly equally distributed between the four restrictive categories. Even in jurisdictions that expressly prohibit the use of age, younger drivers may pay higher automobile insurance premiums if insurers are allowed to rate based on the number of years of driving experience. See, e.g., 10 Colo. CodE REgS. § 2632.4(a) (forbidding discrimination on the basis of age and many other characteristics); CAL. INS. CODE $§ 1861.02(a)(3)$ (allowing use of the number of years of driving experience). And states that have a specific restriction may permit the use of age under certain circumstances, like if there is a proven correlation between accident rate and the characteristic. See, e.g., N.Y. INS. LAW § 2331 (forbidding the state approval of auto insurance plans that consider age, gender, or marital status, "unless such filing is supported by and reflective of actuarially sound statistical data").

${ }_{92}$ No state prohibits the use of age in disability insurance and only three states strongly limit it (Michigan, Pennsylvania, and Texas).
} 


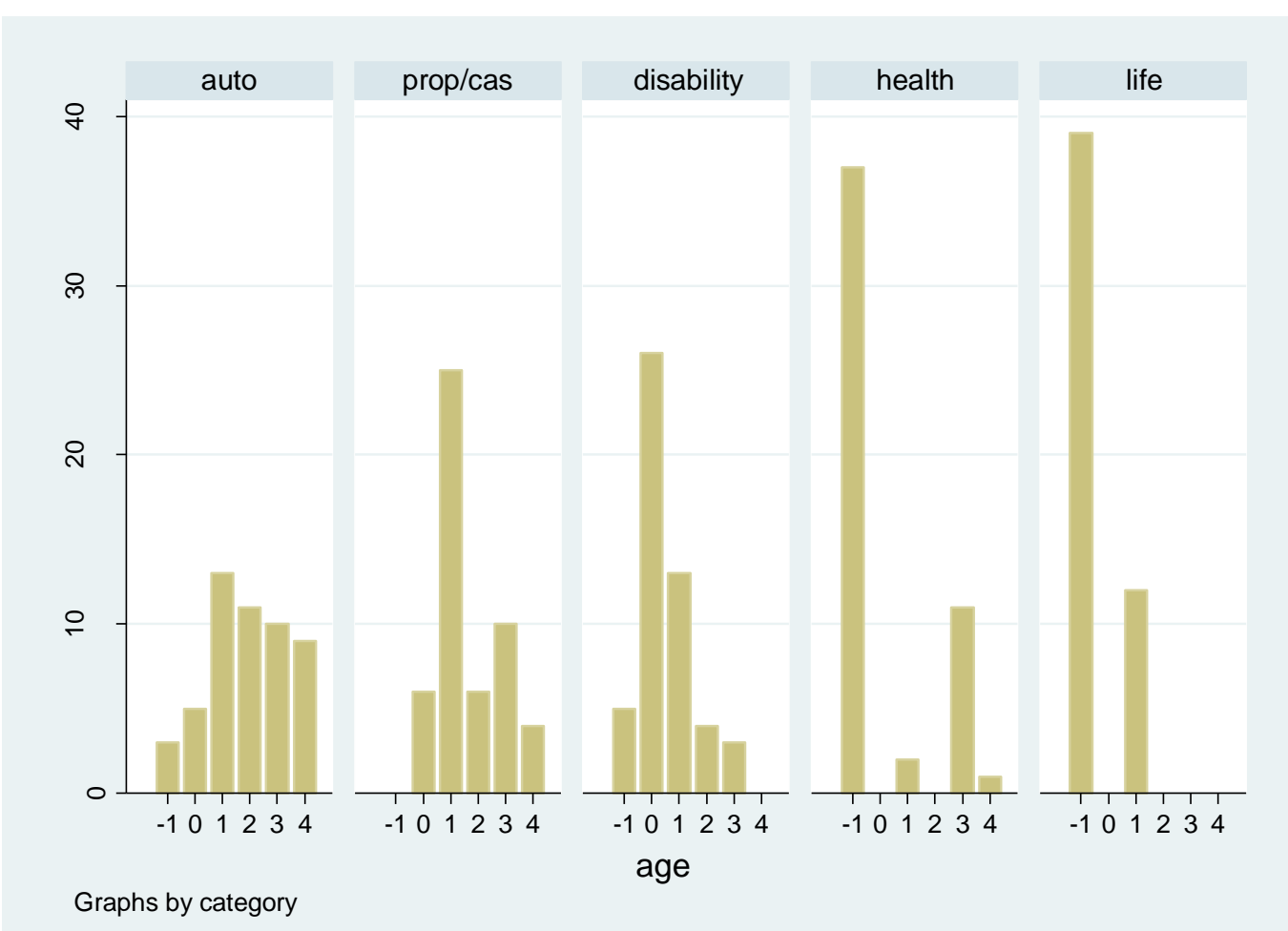

Chart 6: Distribution of States' Scores for Age, by Insurance Line

Because the patterns of cross-line variation with respect to age match the broader patterns of cross line variation, our model can explain these findings in the same way that it explains the broader cross-line variation described in Part B. But prong three of our model also helps to explain the more specific fact that state regulation of age is particularly permissive in the context of health and life insurance. Regulatory restrictions on the use of age in the context of health and life insurance would raise particularly large adverse selection concerns. This is because the magnitude of the correlation between age and death/illness is very large and very well understood by policyholders. Indeed, the connections between age, on the one hand, and the risks of illness and death, on the other, are so intuitive that many deaths and illnesses (such as dehydration) are simply attributed to "old age." 93

\footnotetext{
${ }^{93}$ Lea Brilmayer et al., Sex Discrimination in Employer-Sponsored Insurance Plans: A Legal and Demographic Analysis, 47 U. CHI. L. REV. 505 (1980) ("Age discrimination is so basic in life insurance and annuities that any serious challenge to it seems unlikely.").
} 
Admittedly, our model does have trouble explaining one element of the cross-line regulation of age: the lack of state law specifically regulating the use of age in disability insurance. Prong one could explain this finding if age had no predictive value in disability insurance. But this seems unlikely, although the nature of the connection between age and disability is certainly less clear than it is in the context of health, life, and auto insurance.

\section{Cross-Line Treatment of Credit Score}

The cross-line treatment of credit score discrimination matches the larger trends seen across all characteristics: it is most heavily regulated in auto and property/casualty and less heavily regulated in life, health and disability. Aside from demonstrating this fact, Chart 7 also shows that insurers' use of credit score is specifically addressed by almost every state in property/casualty and auto insurance. ${ }^{94}$ By contrast, many state laws generally do not specifically address the use of credit score in health, life, and disability insurance, where the majority of the laws are coded as either a " 0 " or a " 1. " Where this is not the case, states explicitly permit the use of credit score, and few explicitly restrict it.

\footnotetext{
${ }^{94}$ In auto insurance, the only jurisdiction that does not mention credit score is the District of Columbia.
} 


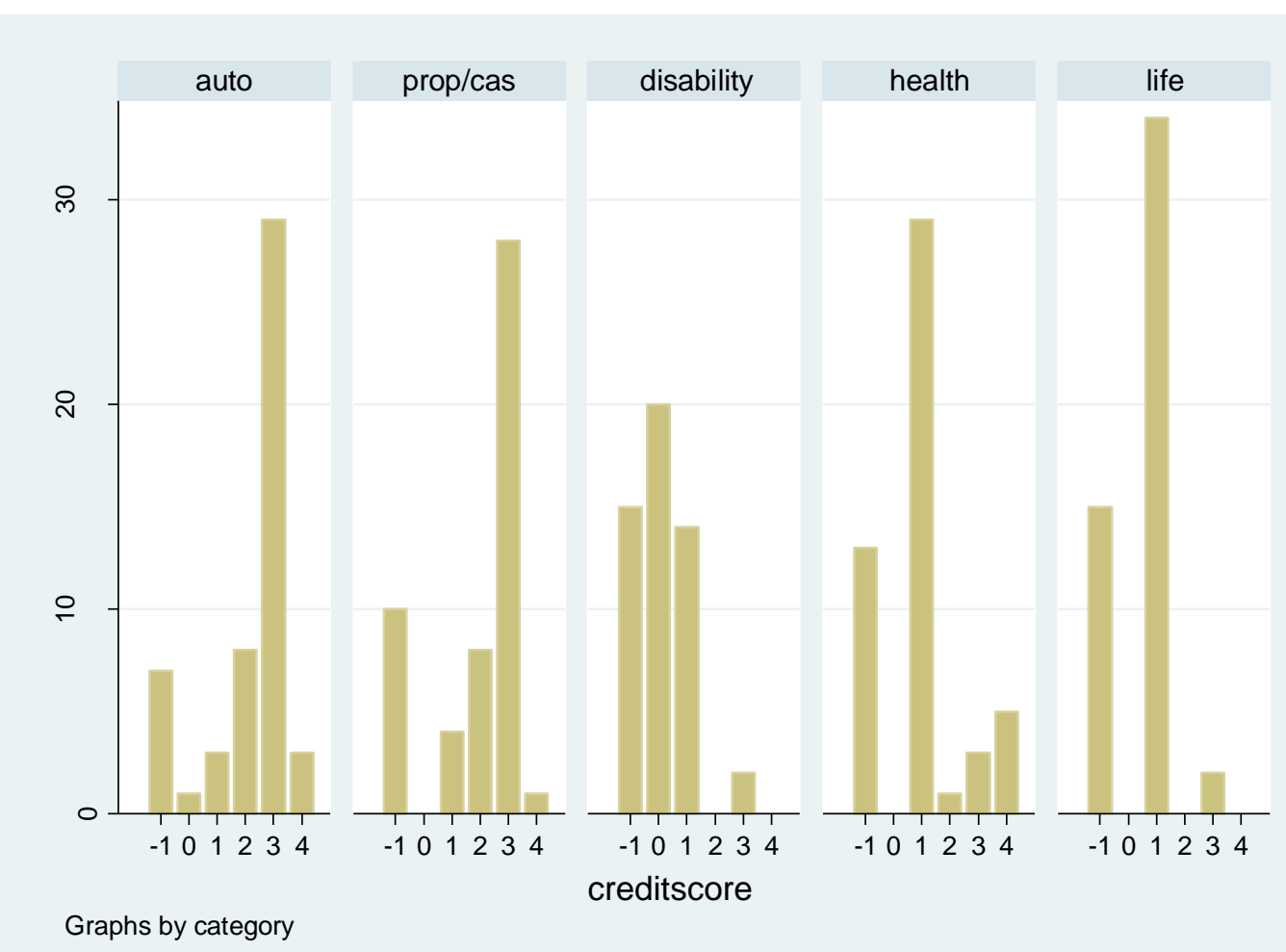

Chart 7: Distribution of States' Scores for Credit Score, by Insurance Line

Once again, these findings are broadly consistent with both general trends and our explanations for these general trends. But our model also provides some more nuanced explanation for these findings. In particular, the fact that credit score is so rarely mentioned in state laws governing health, life, and disability, but specifically addressed in auto and property/casualty, is quite consistent with prong one of our model, the predictive property. Put quite simply, credit score has repeatedly been shown to predict losses in property/casualty and auto insurance. ${ }^{95}$ However, we are unaware of any research suggesting that credit score is a useful predictor of risk in other lines of insurance. Indeed, insurers in these three lines of insurance have not historically used credit information in their underwriting

\footnotetext{
95 See Credit-Based Insurance Scores: Impacts on Consumers of Automobile Insurance: A Report to Congress by the Federal Trade Commission (Jul. 2007), available http://www.ftc.gov/os/2007/07/P044804FACTA_Report_Credit-Based_Insurance_Scores.pdf (discussing widespread use of credit scores in auto and homeowners). The reason why, however, is not well understood. According to the National Association of Independent Insurers, at least, "people who manage their personal finances responsibly tend to manage other important aspects of their life with that same level of responsibility and that would include being responsible behind the wheel of their car or being responsible in maintaining their home."
} 
practices. ${ }^{96}$ Thus, there was never a need to restrict the usage of credit score in these lines. $^{97}$

Our model also explains why the regulation of credit score in property casualty and automobile insurance tends to hover around a strong limitation ("3") rather than a prohibition ("4") in our data. Our second prong, the illicit discrimination property, suggests that there is a rationale for strong regulation in this domain. The core justification for regulating credit score is that it is not causally linked to risk and instead serves as a proxy for socially suspect characteristics like race and income. At the same time, adverse selection, our third prong, at least mildly pushes against the outright prohibition of credit score. The result is a strong prohibition with some states explicitly prohibiting this practice.

\section{Cross-Line Treatment of Race, Religion, and Ethnicity}

Chart 3 above showed that race, ethnicity, and religion (the "big three") are the most intensely restricted characteristics in every line of insurance, with sometimes a full one-point difference between them and the next most restricted characteristic, namely gender. ${ }^{98}$ Surprisingly, though, states do not uniformly prohibit insurers from using race, religion, and ethnicity, a fact we explore at length in related work. ${ }^{99}$ For present purposes, the key issue is the variation in states' regulation of the "big three," which resembles the broader cross-line trends: property/casualty insurance is the most restrictive line of insurance, then auto, health, life and lastly disability insurance.

\footnotetext{
${ }^{96}$ See NAIC, Credit Reports and Insurance Underwriting, White Paper (1997) (“As reported by the American Council of Life Insurance (ACLI) and the Health Insurance Association of America (HIAA), life and health insurers do not use credit reports of the type that are used to establish a person's eligibility for credit..."); Christopher Cruise, How Credit Score Affects Insurance Rates, BANKRATE.COM (2003), available at http://www.bankrate.com/brm/news/insurance/credit-scores1.asp ("So far, spokesmen at the trade associations for health and life underwriters say they don't know of any of their members use credit scoring in underwriting and pricing policies...”).

${ }^{97}$ There is some anecdotal evidence that life, disability, and health insurers may be experimenting with using credit score to rate policyholders. If so, then this suggests that states should be cautious in restricting limitations on insurance underwriting to lines in which carriers presently use the characteristic at issue. Doing so can produce unjustified discrepancies in legal restrictions if insurers' underwriting patterns change.

${ }^{98} I d$. Interestingly, the prohibition on using religious affiliation is stricter on average than the prohibition on using race or ethnicity.

${ }^{99}$ See Understanding Insurance Antidiscrimination Law, supra.
} 
Avraham et al.:

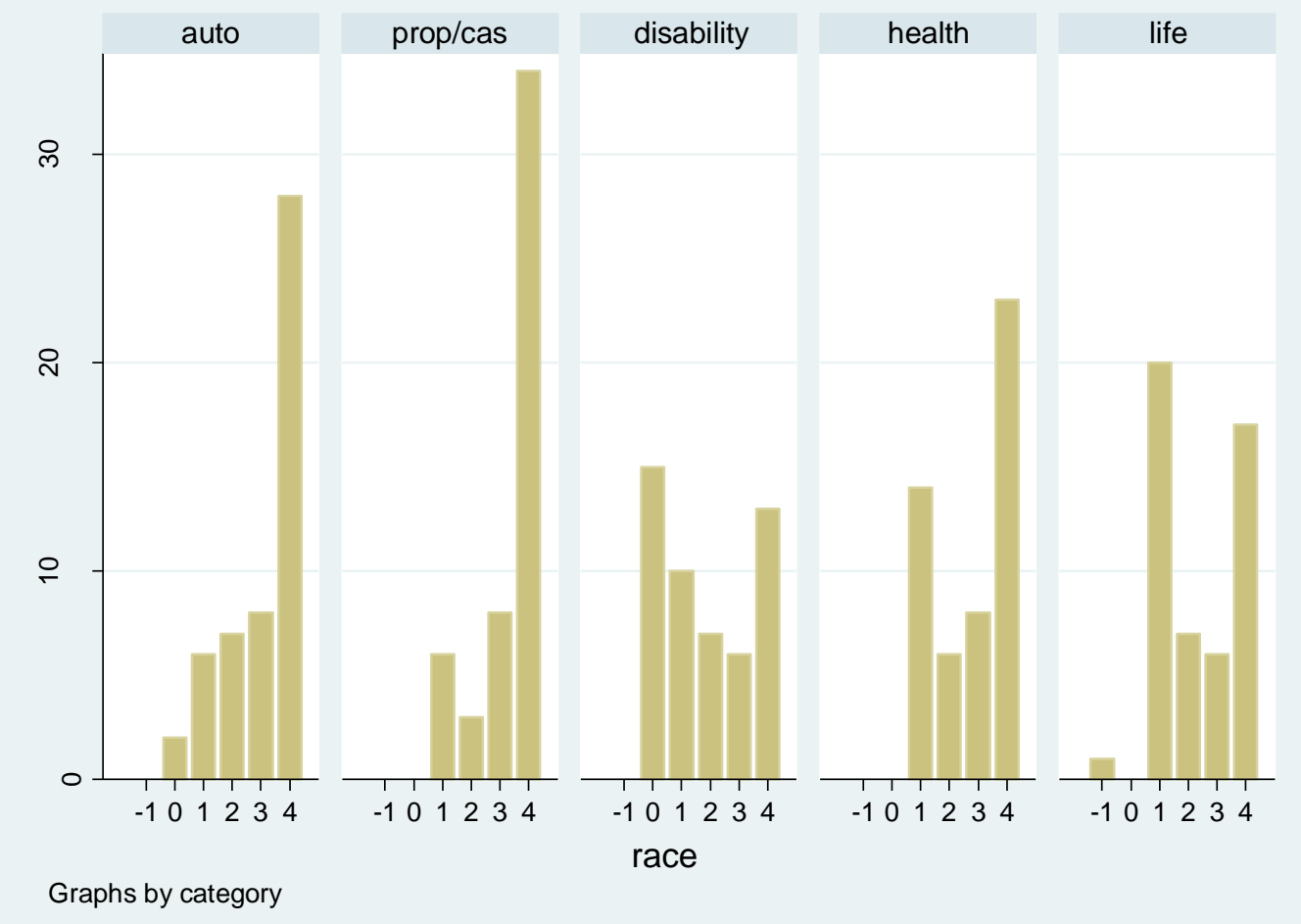

Chart 8: Distribution of States' Scores for Race, by Insurance Line

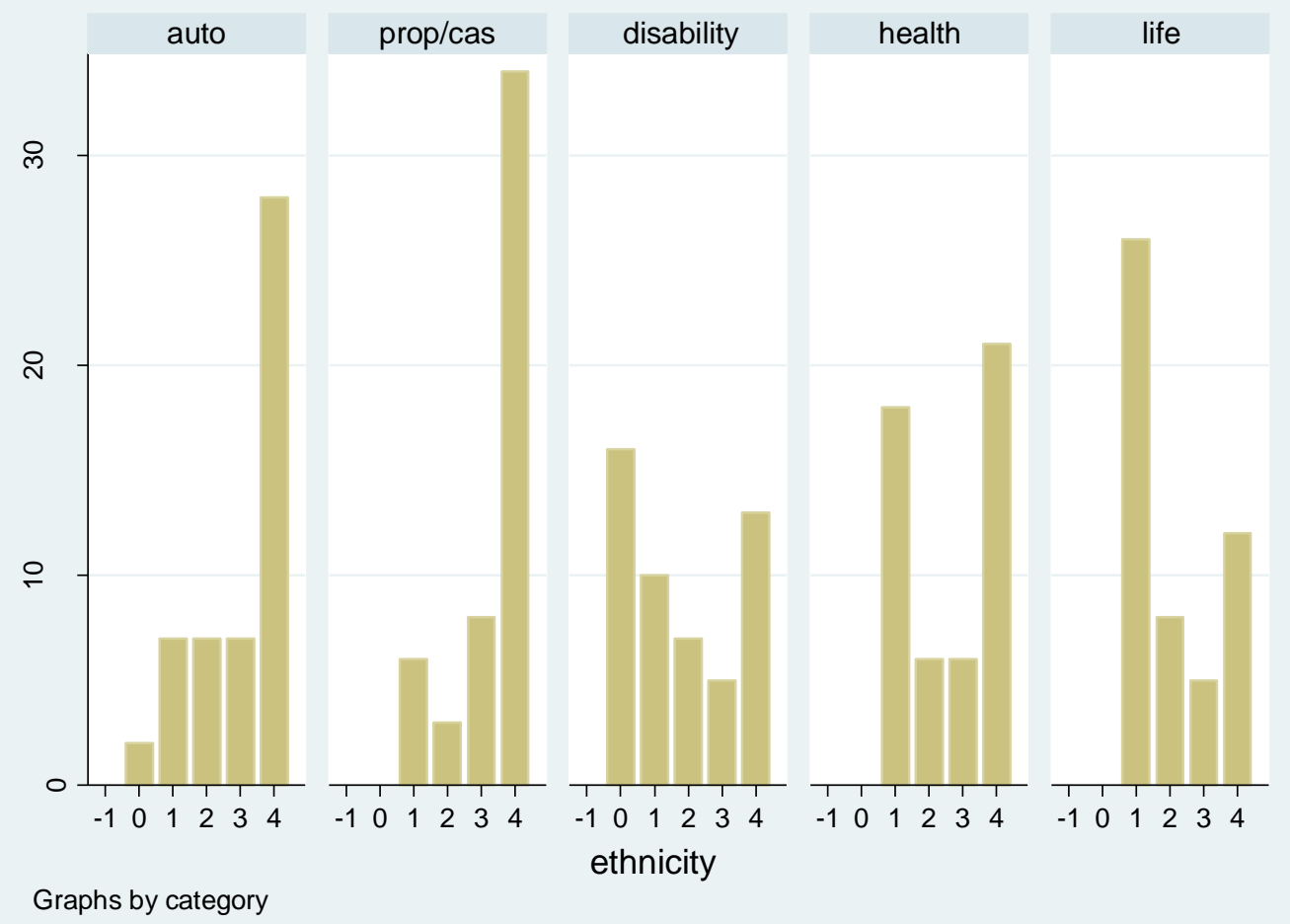

Chart 9: Distribution of States' Scores for Ethnicity, by Insurance Line 


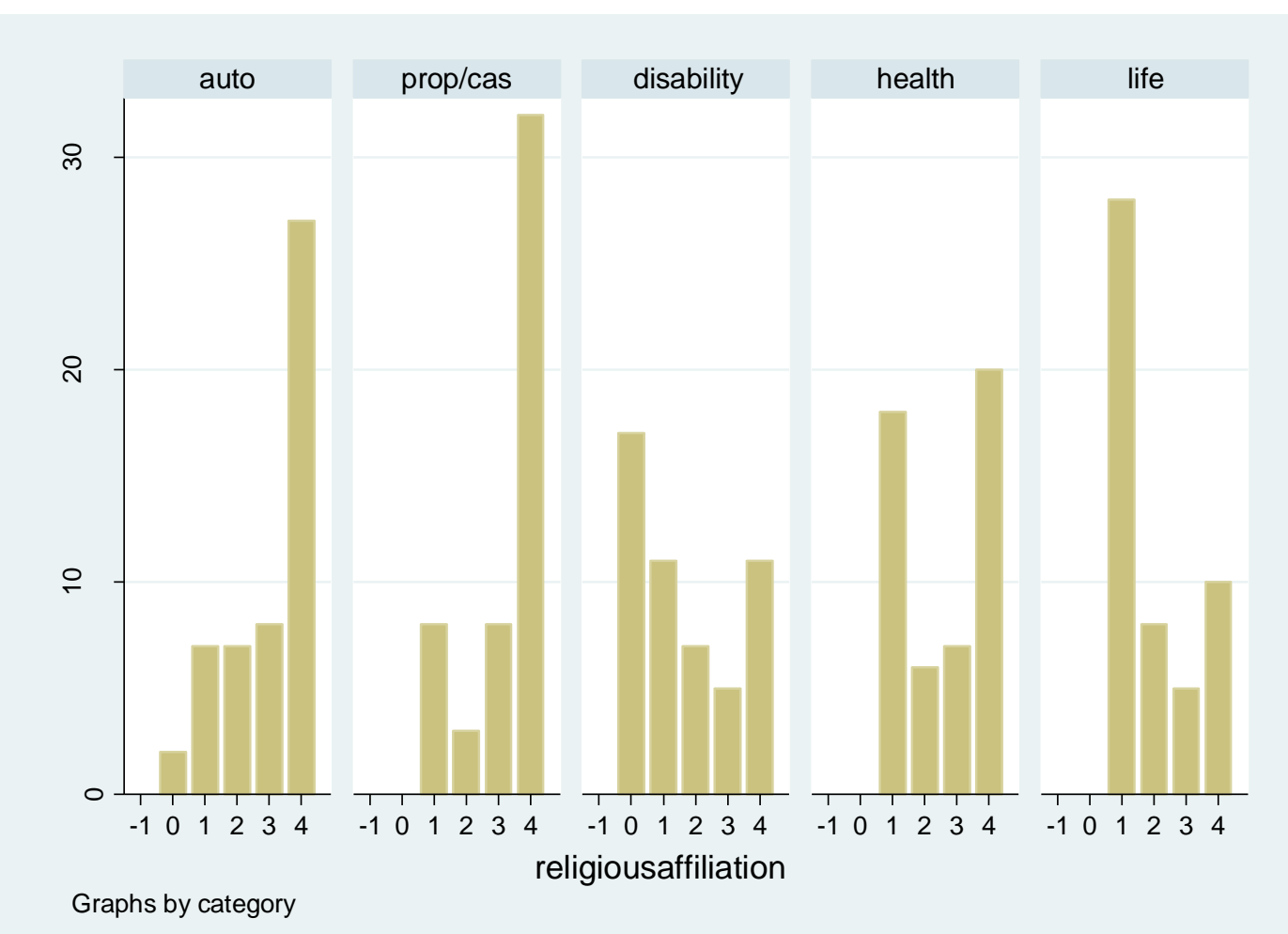

Chart 10: Distribution of States' Scores for Religion, by Insurance Line

At least with respect to the big three, however, we think that the best explanation for this pattern is not the adverse selection property, which was the principal explanation we offered for cross-line variation that was no trait specific. Instead, it is likely that the patterns found in each of the charts above are better explained by prong 1 of our model: the predictive property. ${ }^{100}$ There is substantial historical precedent for homeowner and automobile insurers using race, or proxies for race, ethnicity, and religion in their underwriting. ${ }^{101}$ By contrast, there is much less historical precedent for race, ethnicity, or religion ever been used in health, life, or disability insurance, and it is not immediately clear that these factors would offer much predictive value to insurers even if they were to use them. ${ }^{102}$

\footnotetext{
${ }^{100}$ To be sure, there are other potential explanations. For instance, perhaps state regulators and their constituents are under the mis-impression that federal law already bans the use of these characteristics in all lines of insurance.

${ }^{101}$ See, e.g., insurance redlining literature.

${ }^{102}$ The one exception was industrial life insurance, which amounts to a form of burial insurance. For years this insurance was classified according to race, which apparently was never considered illegal, but the practice died out
} 
If at all, the question is why not every state in the country prohibits the use of race, ethnicity, and religion. In other words, why do some states just limit the use of race? In our previous paper we offered a number of theories. Perhaps state regulators and their constituents are under the impression that federal law already bans the use of these characteristics. Or, maybe state legislatures that have not adopted bans for the big three are of the view that insurers have stopped using race, ethnicity, and religion already and thus that a law prohibiting their use would simply be unnecessary.

We are still left with a puzzle though: why are auto and property/casualty more prohibitive of using the "big three" for risk classification purposes than health, life, and disability. Like in the case of credit score above we believe that adverse selection does not provide an adequate answer. Even if these characteristics have predictive value for health, life, or disability insurance, unlike the case of credit score none of these lines actually permits taking these characteristics into account. We therefore believe that the best explanation is that these characteristics fall under the general restrictions rules (coded as 1), which explains the low average score.

\section{Cross-Line Treatment of Zip Code}




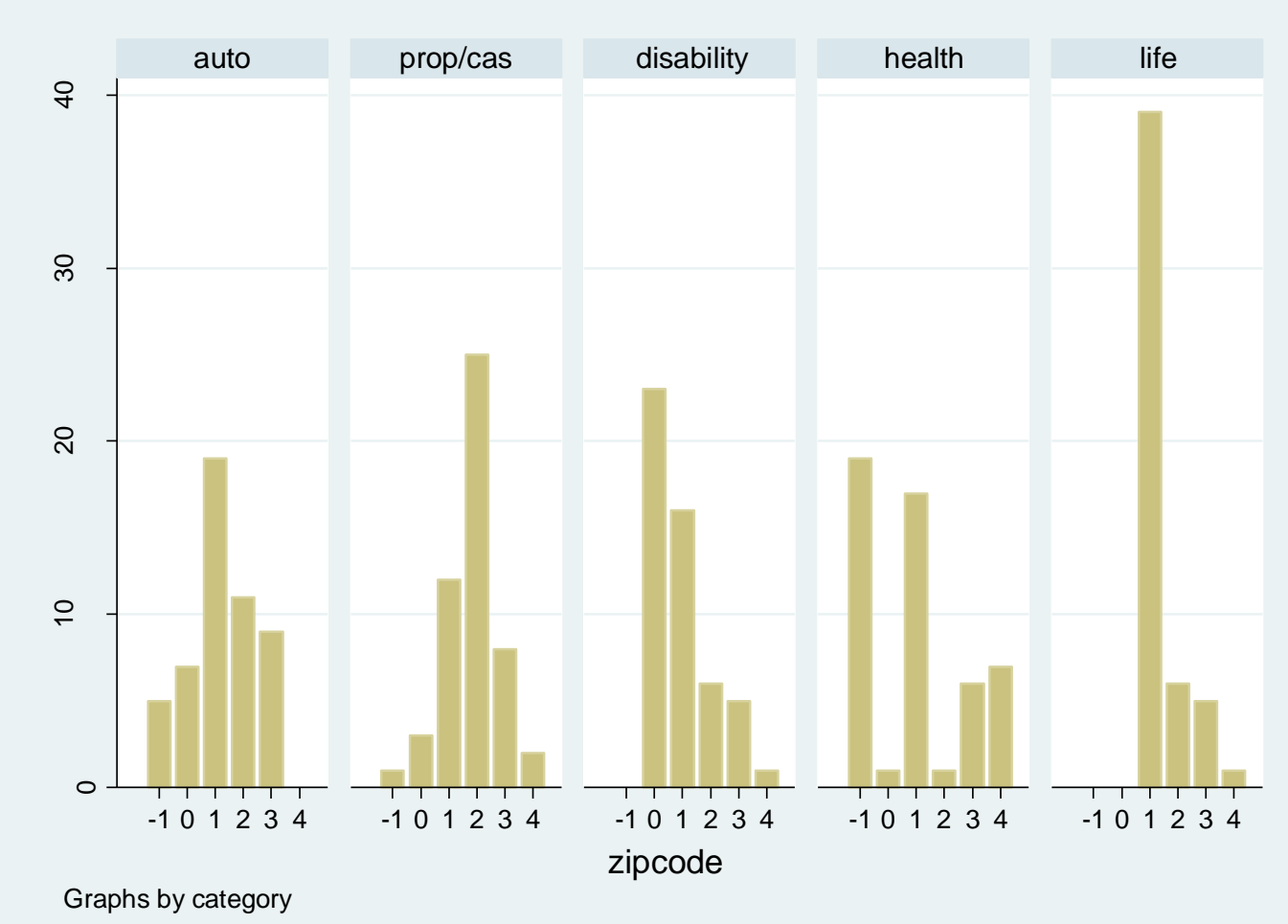

Chart 11: Distribution of States' Scores for Zip Code, by Insurance Line

States' regulation of discrimination on the basis of policyholder zip code varies along the same lines that generic antidiscrimination rules vary across lines: it is regulated most restrictively in property/casualty insurance and least restrictively in health and disability insurance. Chart 11 demonstrates this fact, while revealing that state laws specifically mentioning zip code are much more common in auto, property/casualty, and health insurance than they are in life and disability insurance. Chart 11 also shows that almost 20 states explicitly permit health insurers to classify policyholders' risks based on their zip code, compared with only five states which permit it in automobile insurance, and only one in property/casualty insurance.

Once again, these results are consistent with our model. First, the fact that state law specifically mentions zip code much more frequently in health, property/casualty, and auto than in disability and life insurance is consistent with Prong 1 of our model. Zip code has clear predictive value in the lines where states tend to regulate it. Thus, zip code is quite relevant to health insurance risk, as there 
is substantial geographical variation in the general cost level of medical services in different geographic area. ${ }^{103}$ Zip code also has predictive value for property/casualty insurance because it can provide information about the risk of fire, the likelihood of theft, the cost of rebuilding, and numerous other factors that are constitutive of a homeowner's risk. ${ }^{104}$ Similarly, zip code can help predict auto policyholders' risk because it provides information about traffic patterns, density, and risk of loss. ${ }^{105}$ Indeed, the vast majority of states do not leave zip code unregulated in auto insurance. Therefore the first prong of our model is helpful in explaining the variation in zip code regulations. By contrast, it is unclear whether zip code has any capacity to predict risk for disability and life insurance (at least once other underwriting factors are used). ${ }^{106}$

As for the disparate treatment of zip code for health insurance, on the one hand, and automobile and property/casualty insurance on the other, this too is consistent with our model. The relatively strong restrictions on using zip code in automobile and homeowners insurance stems from the fact that commentators and consumer groups have argued that zip codes are, or in the past have been, used by insurers as proxies in the home and auto insurance context for socially suspect characteristics, such as race. Although the same concern might apply in the health insurance domain, adverse selection pushes in the opposite direction given the large geographical variation in the costs of health care. The magnitude of that variation makes adverse selection a much larger threat. ${ }^{107}$

\section{Cross-Line Treatment of Sexual Orientation}

As Chart 12 shows, the most restrictive line with respect to sexual orientation is health, followed by life insurance. By contrast, sexual orientation is less regulated in auto, property/casualty, and disability insurance, with many states having a no-law score with respect to sexual orientation.

\footnotetext{
${ }^{103}$ Dartmouth Atlas of Health Care. http://www.dartmouthatlas.org/

${ }^{104}$ The ISO evaluates public fire protection capabilities. See http://www.iso.com/faq/ISO-FAQ/The-PublicProtection-Classification-PPC-Program.html.

${ }^{105} \mathrm{http}: / /$ www.latimes.com/business/custom/yourmoney/la-fi-lazarus6apr06,0,693725.column?page=2

${ }^{106}$ Mortality and disability rates should also depend on crime rates and accident rates, both of which depend on zip code.

${ }^{107}$ See Part I.
} 


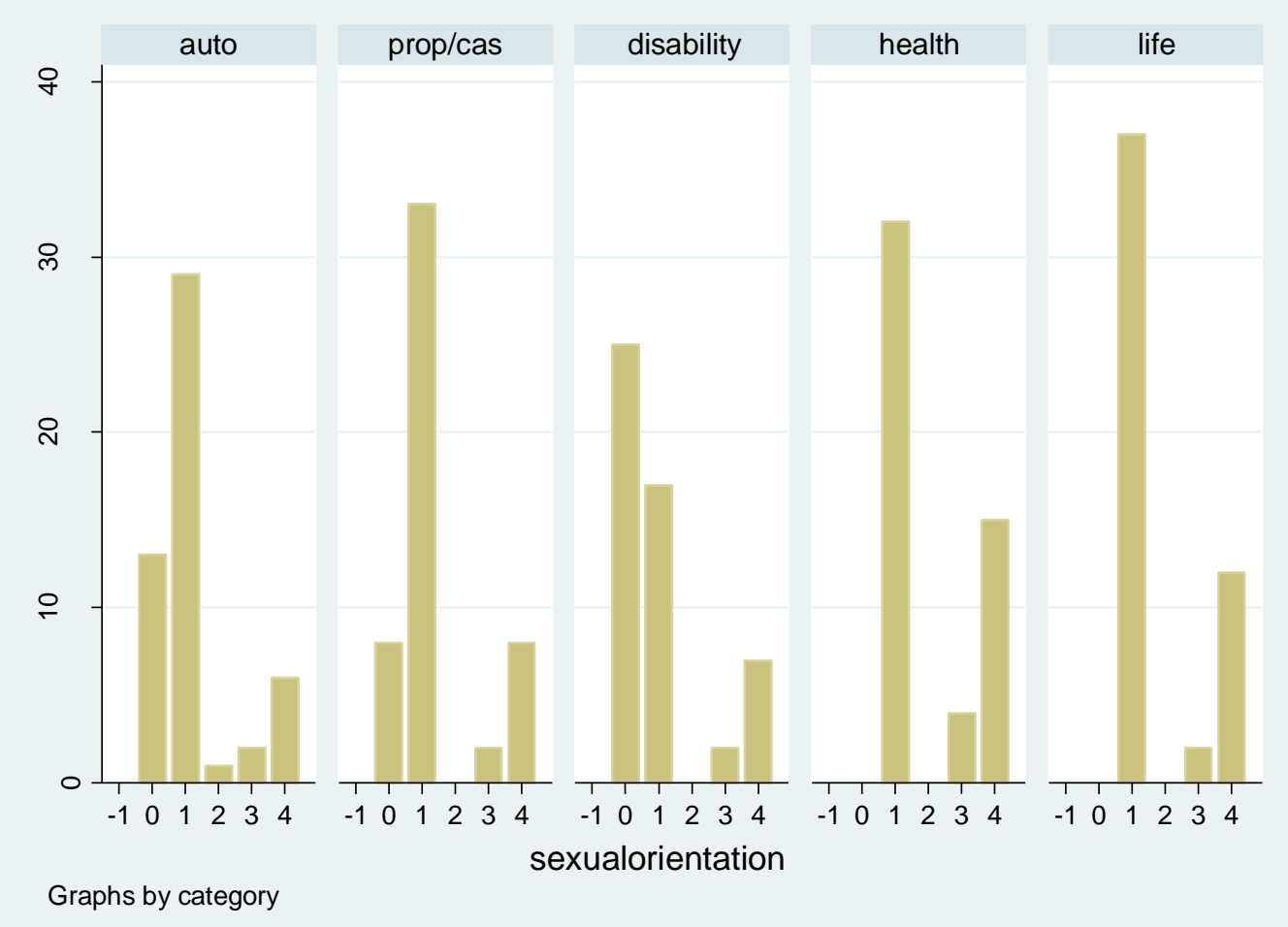

Chart 12: Distribution of States' Scores for Sexual Orientation, by Insurance Line

Once again, these results are largely consistent with our model. First, it is quite clear that sexual orientation has no predictive power with respect to auto, prop/casualty and disability. This explains why a number of states in these lines of insurance have no law on point (our first prong). By contrast, at several points in recent history sexual orientation was perceived to have predictive power with respect to healthcare costs and an increased mortality rate via its perceived association (whether empirically proven or not) with AIDS. This explains why all states in health and life insurance chose to regulate it. Second, sexual orientation has over the past decades become recognized as deserving protection against discrimination, as discussed above. ${ }^{108}$ Thus, there is a strong fairness based argument that sexual orientation should not be used in the lines where it does have perceived predictive power: life and health insurance. Third, the number of individuals who actually are gay and have AIDS is quite small relative to the aggregate pool of policyholders. As a result, prohibiting discrimination on this basis is unlikely to cause any substantial amounts of adverse selection.

\footnotetext{
${ }^{108}$ See Part III.A.
} 


\section{Conclusion}

Insurance regulations vary between states, between characteristics, and between insurance lines. This Article has presented empirical findings that demonstrate a tremendous amount of cross-line and cross-characteristic variation in insurance regulation. Although one might expect that states would subject a characteristic to the same amount of regulation for all insurance lines, this is not the case.

Yet both the cross-line and cross-characteristic variation that we do find is hardly random. In fact, most of this variation, we argue, can be explained by a simply three-pronged model that emphasizes the predictive value of a characteristic in a particular line, the extent to which that characteristic is socially illicit, and the risk that limiting discrimination on the basis of that characteristic will result in adverse selection. Although this reduced-form model cannot perfectly explain variation in state insurance anti-discrimination law, it comes quite close to doing so.

This Article thus provides a reasonably simple model that explains much of insurance anti-discrimination law in practice. By focusing on our three-prong model - the predictive property, the adverse-selection property, and the illicitdiscrimination property - we should be able to predict the shape of insurance antidiscrimination law in other contexts. Take, for example, the characteristic of marital status. We happen to know that some states regulate insurers' use of this characteristic, although we have made no systematic study of the issue. Based on the findings of this Article, however, we would predict that the pattern of state regulations affecting insurers' use of marital status would turn on the three prongs we have identified. 